\title{
Review Article \\ Cell Surface Remodeling by Plasmin: A New Function for an Old Enzyme
}

\author{
Elena I. Deryugina and James P. Quigley \\ Department of Cell Biology, The Scripps Research Institute, 10550 North Torrey Pines Road, La Jolla, CA 92037, USA \\ Correspondence should be addressed to Elena I. Deryugina, deryugin@scripps.edu and James P. Quigley, jquigley@scripps.edu
}

Received 2 May 2012; Accepted 1 June 2012

Academic Editor: Lindsey A. Miles

Copyright ( $) 2012$ E. I. Deryugina and J. P. Quigley. This is an open access article distributed under the Creative Commons Attribution License, which permits unrestricted use, distribution, and reproduction in any medium, provided the original work is properly cited.

\begin{abstract}
Plasmin, one of the most potent and reactive serine proteases, is involved in various physiological processes, including embryo development, thrombolysis, wound healing and cancer progression. The proteolytic activity of plasmin is tightly regulated through activation of its precursor, plasminogen, only at specific times and in defined locales as well as through inhibition of active plasmin by its abundant natural inhibitors. By exploiting the plasminogen activating system and overexpressing distinct components of the plasminogen activation cascade, such as pro-uPA, uPAR and plasminogen receptors, malignant cells can enhance the generation of plasmin which in turn, modifies the tumor microenvironment to sustain cancer progression. While plasmin-mediated degradation and modification of extracellular matrix proteins, release of growth factors and cytokines from the stroma as well as activation of several matrix metalloproteinase zymogens, all have been a focus of cancer research studies for decades, the ability of plasmin to cleave transmembrane molecules and thereby to generate functionally important cleaved products which induce outside-in signal transduction, has just begun to receive sufficient attention. Herein, we highlight this relatively understudied, but important function of the plasmin enzyme as it is generated de novo at the interface between cross-talking cancer and host cells.
\end{abstract}

\section{Introduction}

The plasminogen activation (PA) system plays an important role in various pathophysiological processes, including vascular and tissue remodeling, tumor development, and cancer progression [1-7]. In the cancer arena, which will be in the spotlight of this paper, some of the distinct molecular components of the PA system received much attention because of their rate-limiting role in plasmin generation or because their overall expression was linked to progression of certain types of cancers and patient outcome (see some original publications [8-15] and summarizing reviews [16-18]). Hence, the main focus of studies within the PA/plasmin system during the last two decades was placed on the plasminogen activators (tPA and uPA), their inhibitors (PAI-1 and PAI-2), the $\mathrm{UPA}$ receptor ( $\mathrm{UPAR}$ ), and various plasminogen receptors, whereas the investigation of specific effects of the actual, cleavage-executing enzyme, plasmin, appeared to be somewhat abandoned by mainstream cancer research. Moreover, a tendency has been established to ascribe direct plasmin-mediated functions, such as cleavage of certain matrix proteins or activation of specific latent growth factors, to the activity of uPA $[19,20]$. Conversely, plasmin involvement in vivo is generally implied in the outcomes of uPA functionality without conclusive evidence of de novo generated plasmin or measuring or inhibiting its enzymatic activity. In addition, being a potent proteolytic enzyme, plasmin was shown early to cleave and degrade in vitro a broad range of proteins, frequently in a test tube or assay plate. These early findings may have hindered the later investigations of precise plasmin targets and functions in a live animal, especially within the context of the tumor microenvironment, for which the list of nonfibrin proteins proven to be actual in vivo plasmin substrates is rather limited. In this paper 
we will concentrate on the evidence directly linking de novo generated activity of plasmin and its catalytic manifestations in cancer-related in vivo settings.

\section{Soluble and Cell Surface Systems for Active uPA and Plasmin}

Plasminogen is converted to plasmin via cleavage of the Arg561-Val562 peptide bond [21] by either tissue-type plasminogen activator (tPA) or urokinase-type plasminogen activator (uPA). The cleavage results in generation of the $\mathrm{N}$-terminal $\alpha$ chain, containing five kringle domains with lysine-binding sites, and the $\beta$ chain, containing the catalytic triad of His603, Asp646, and Ser741 [22]. Produced by the liver, plasminogen circulates at relatively high concentrations (approximately $2 \mu \mathrm{M}$ ), making it an abundant zymogen in plasma and also in interstitial fluids, where its concentration can be increased upon inflammation or injury through exudation from the vascular system [23]. Therefore, plasminogen activation by its specific activators is one of the ways to efficiently regulate plasmin functions. In the blood stream, plasminogen is activated mainly by tPA, generating the enzyme responsible for lysis of fibrin clots. In wounded tissues undergoing repair or in the tumor microenvironment undergoing constant remodeling, plasmin is generated through uPA-mediated activation [1]. The enhanced expression of single-chain pro-uPA by cancer cells and the ability of malignant tumor cells to activate pro-uPA into the twochain, catalytically active uPA $[24,25]$, as well as regulation of uPA activity by the specific inhibitors, PAI-1 and PAI-2 [26], are all critical factors in plasmin generation and consequently, regulation of plasmin-mediated cell functions. A unique mechanism for plasminogen activation involves microparticles which are produced by endothelial cells under stress conditions and provide abundant surface for uPAR/uPA-mediated plasmin generation [27].

Since the major components of the uPA/plasmin systems are secreted proteins, activation of plasminogen by uPA can occur extracellularly, albeit in close proximity to the uPAexpressing cancer or endothelial cell. Pro-uPA activation by trace plasmin, constituting a distinct feedback mechanism leading to further amplified plasmin generation, also can be achieved directly on tumor cell surfaces through the binding of pro-uPA to its specific receptor, uPAR. Our findings with the highly disseminating variant of human prostate cancer cells, PC-hi/diss, indicate that most of the in vitro generated two-chain uPA quickly dissociates from the cell surface and accumulates in the conditioned medium, but is undetectable in the cell lysates (Casar, unpublished observations). Therefore, only a fraction of plasmin activity could be demonstrated being directly generated by the cell surfacebound uPA [28]. It is possible that UPAR and some plasminogen receptors initiate generation of uPA and plasmin at the cell surface, but do not retain the respective activated enzymes for a long time. Supporting this notion, it has been demonstrated that plasmin and plasminogen bind to distinct sites on one of the plasminogen receptors, S100A10 [29]. This finding implies that proteolytic conversion of plasminogen would result in plasmin translocation in cis within the same plasminogen receptor molecule or, more likely, in trans between two receptor molecules. Although binding of plasmin to plasminogen receptors and uPA to UPAR is viewed as a mechanism for sequestration or escape of active enzymes from their natural inhibitors, respectively $\alpha 2$-antiplasmin and PAI-1/PAI-2 [30], the release of active $\mathrm{uPA}$ and plasmin from the cell surface may actually represent a mechanism allowing for efficient re-usage of the respective zymogen-binding molecules during recurring cycles of enzyme generation.

\section{Role of Cell Surface Plasminogen-Binding Receptors in Pericellular Localization of uPA-Generated Plasmin}

Whether activated uPA remains bound to cell membrane via UPAR or is released but maintained in a pericellular pool, uPA-generated plasmin will be localized to the close vicinity of the tumor cell surface. This scenario is further supported by existence of a number of cell surface plasminogen-binding molecules [31]. These receptors present the bound plasminogen to uPAR-bound uPA or pericellular soluble uPA, and therefore localize any generated plasmin to the cell surface or to immediate proximity of the cell. Besides functioning as plasminogen receptors on tumor cells, plasminogen-binding molecules are also found on other cell types that might reside within or influx into the tumor microenvironment. The interplay between tumor cells and host cells, such as endothelial cells and activated myofibroblasts, can induce various signaling pathways as a result of uPA-mediated conversion of plasminogen bound to its receptors. This tumor-host crosstalk resulting in plasmin generation might play an important role in cancer progression through regulation of cell proliferation, apoptosis, angiogenesis, adhesion, migration, and invasion. In addition, expression of plasminogen receptors by host blood leukocytes might facilitate activation of juxtapositioned inflammatory cells presenting surfacebound plasminogen to the active uPA bound to uPAR on either tumor or endothelial cell. The latter scenario becomes even more relevant when one considers that angiogenic tumor tissues are invariably infiltrated with various types of inflammatory leukocytes [32].

Numerous cell surface molecules have been shown to be capable of binding plasminogen, thereby facilitating its conversion into plasmin. Many of these plasminogenbinding receptors are intracellular molecules having wellknown specific roles in the cytoplasm or nucleus. However, being translocated to the plasma membrane, these "unusually" displayed molecules apparently serve for plasminogen trapping. Most of these cell membrane molecules possess Cterminal lysines, which allow them to function as plasminogen receptors via direct binding of plasminogen through the lysine-binding sites located in its kringle domains. A glycolytic enzyme enolase-1 ( $\alpha$-enolase) was among the first C-terminal lysine-containing plasminogen receptors identified on the surface of peripheral blood cells [33]. Recently, enolase-1 was shown to regulate, via plasminogen-binding 
mechanisms, monocyte recruitment to injured lungs and to play a central role in inflammatory lung disease [34].

Another "unusually" localized plasma membrane molecule that possesses a C-terminal lysine is histone $\mathrm{H} 2 \mathrm{~B}$, one of the main 5 histone proteins involved in the maintenance of chromatin structure in eukaryotic cells. It originally was shown to serve as a plasminogen receptor on the cell surface of neutrophils and monocytic cells [35], and later its plasminogen-binding capability was implicated in the regulation of macrophage recruitment [36]. Cell surface forms of actin were also identified as plasminogen receptors responsible for stimulation of plasminogen activation and plasmin-mediated processing of prohormones produced by neurosecretory cells [37].

A number of plasminogen-binding receptors belong to the families of calcium-binding proteins localized to the cell membrane as homodimers [38]. Annexin 2 (annexin II) is a member of annexin family, whereas S100A4 and S100A10 belong to the S100 family. In addition to plasminogen, annexin 2 can independently bind tPA, accelerating cell surface conversion of plasminogen to plasmin $[39,40]$. Furthermore, two molecules of annexin 2 and two molecules of S100A4 or S100A10 (p11) can generate heterotetramers $[29,41,42]$, thereby even further enhancing the catalytic efficiency of plasmin production. The specific functions of these molecules as plasminogen receptors are described in the designated sections of this issue. In relation to cancer biology, the role of annexin2 has been recently reviewed in [38]. Specifically, attenuation or loss of S100A10 expression in tumor cells was shown to result in a significant reduction of plasmin generation, concomitant with a dramatic inhibition of extracellular matrix degradation, invasiveness and metastasis $[29,43]$. Annexin-mediated assembly of plasminogen and tPA on monocytes/macrophages contributed to the generation of plasmin activity in vitro and thus, facilitated matrix remodeling, invasion of monocytes and their differentiation into macrophages [44]. Plasminogen binding to the annexin $2 \mathrm{~A}$ and S100A10 complex on human monocytes was also implicated in uPA-mediated generation of plasmin and plasmin activity, which in turn increased MMP-1 synthesis via multiple signaling pathways, including ERK1/2, p38 MAKK, cyclooxygenase-2, and $\mathrm{PGE}_{2}$ [45]. PKC-dependent phosphorylation of annexin 2 was reported to be induced by plasmin generated form plasminogen bound to the annexin A2-S100A10 heterotetramer on the surface of endothelial cells [46]. Recently, the expression of S100A10 in macrophages was shown to be essential for their recruitment to the sites of primary tumor formation in murine Lewis lung carcinoma and T241 fibrosarcoma models [47].

All the aforementioned plasminogen receptors lack signal sequences and transmembrane domains and therefore their cell surface location is supposed to be regulated by yet undetermined pathways [48]. In contrast, the most recently discovered plasminogen receptor, Plg- $\mathrm{R}_{\mathrm{KT}}$, not only possesses a C-terminal lysine exposed on the cell surface, but has been predicted to have two transmembrane helix domains and four-amino acid cytoplasmic-loop, assuring its true transmembrane nature [49]. The data have demonstrated that Plg- $\mathrm{R}_{\mathrm{KT}}$ is highly colocalized with uPAR and also suggested direct interactions with tPA, thereby implicating plasminogen activation through the mechanisms established for other plasminogen receptors. Plg- $\mathrm{R}_{\mathrm{KT}}$ has been shown to play a critical role in chemotactic migration and Matrigel invasion of macrophages in vitro and peritoneal macrophage recruitment in mice [50]. Originally discovered on the surface of monocytic cells, this novel transmembrane plasminogen receptor was found also on neuronal, leukemic, and breast cancer cells. In neuronal cells, this plasminogen receptor stimulates plasminogen activation and modulates catecholamine release and neurosecretory cell functions [51]. The molecular structure of Plg- $\mathrm{R}_{\mathrm{KT}}$ indicates its translocation to the plasma membrane by one of the known mechanisms established for transmembrane proteins. Therefore, it appears that the transmembrane Plg- $\mathrm{R}_{\mathrm{KT}}$ is the only member of a redundant family of plasminogen-binding molecules that is "properly" translocated to the cell surface for plasminogen binding. It is also likely that Plg- $\mathrm{R}_{\mathrm{KT}}$ will be demonstrated to play a major role in plasmin generation in vivo and therefore in plasmin-dependent processes involved in tumor cell dissemination.

\section{Lung Retention as a Model to Analyze De Novo Generation of Plasmin during Tumor-Host Cell Interactions}

To discriminate the in vivo contribution of individual components of the uPA/plasmin system to plasmin activity, de novo generation of which could be quantified and related to survival and colonization potential of tumor cells, we have recently introduced a mouse lung retention model. This model is based on intravenous inoculations of human tumor cells into mice with defined genetic backgrounds, for example, wild-type versus uPA, tPA, or plasminogen knock-out mice. Complementing or contrasting the different host backgrounds, inoculated tumor cells can either express or lack specific components of the PA/plasmin system; for example, the tumor cells can be positive or negative for UPAR, or express only single-chain uPA zymogen or both singleand two-chain uPA. Different amounts of plasmin are generated, depending on the presence of distinct components of the uPA/plasmin system provided either by the donor cells or the host microenvironment. Furthermore, the levels of de novo generated plasmin positively correlate with the actual numbers of survived tumor cells in the lung tissue, thereby predicting relative levels of long-term colonization by tumor cells with different phenotypes.

Our lung retention model is depicted in Figure 1. Briefly, tumor cells are inoculated into the tail vein of mice. Within $2 \mathrm{hr}$ following cell inoculations, the majority of tumor cells are arrested in the capillary network of the lungs. Because of cell clearance and proapoptotic pressure, only a fraction of injected cells survives in the lungs by $24 \mathrm{hr}$. The mice are sacrificed at indicated time points by an overdose of anesthetics, the blood is collected into heparin-containing tubes to provide the source of plasma for measuring plasmin activity, 


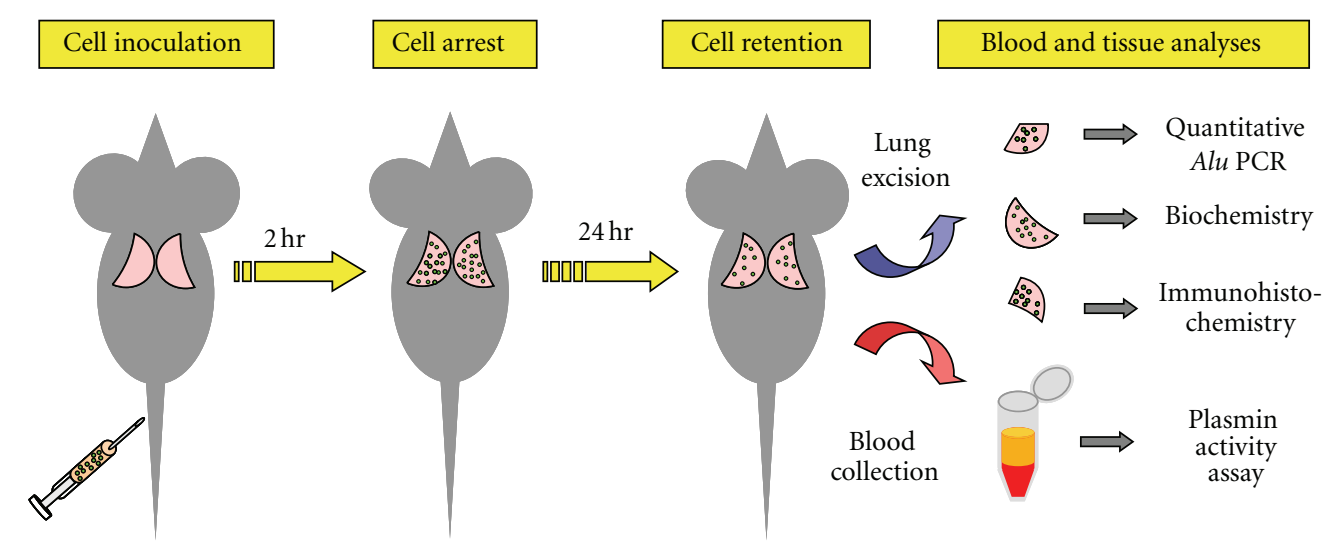

FIGURE 1: Lung retention model to study in vivo tumor cell survival and signal transduction as they relate to generation of plasmin activity.

while the lungs are excised for further quantitative humanspecific Alu PCR analysis of actual tumor cell numbers. Lung tissue can also be analyzed biochemically for expression of human or host proteins, for example, for activation of signal transduction molecules, and analyzed by immunohistochemistry for tissue localization of tumor cells relative to the lung endothelial, stromal, and inflammatory cells.

The collected cell-free plasma is analyzed for plasmin activity by S2251 peptide cleavage assay (Figure 2(a)). To determine the levels of de novo generated plasmin, the background levels of peptide cleavage activity in plasma collected from control mice that did not receive any tumor cells are subtracted from the data obtained for mice inoculated with human tumor cells. By using this model, we have demonstrated that intravenously injected aggressive prostate carcinoma cells, PC-hi/diss, expressing activated two-chain uPA [28], facilitate generation of plasmin in plasminogencompetent mice [52]. As a proof of principle, the lack of the plasmin precursor in plasminogen knock-out mice completely abrogates de novo generation of plasmin, whereas supplementing of plasminogen knock-out recipients with plasmin [52] or plasminogen (Figure 2(a)) almost completely restores plasmin generation, indicating that the activity of plasmin detected in the plasma of wild-type mice indeed reflects newly generated active enzyme.

In addition to monitoring plasmin generation, the levels of tumor cell vascular arrest and lung retention have been determined by Alu PCR of lung tissue collected, respectively, at $2 \mathrm{hr}$ and $24 \mathrm{hrs}$, after cell inoculations (Figure 2(b)). It is important that the levels of vascular arrest in the lungs determined at $2 \mathrm{hr}$ after cell inoculations are similar between experimental cell variants and not affected by genetic backgrounds of either recipients or donor cells. Meeting this criterion is required to properly correlate the differentials in lung retention at $24 \mathrm{hr}$ to the differences in cell survival rather than cell clearance. Thus, there is no difference in $2 \mathrm{hr}$ vascular arrest of tumor cells regardless of plasminogen competence of recipients (Figure 2(b)). However, the genetic ablation of plasminogen results in diminishment of cell retention levels measured at $24 \mathrm{hr}$ in the lung tissue. Concomitant with the rescue of plasmin production, supplementation of plasminogen-deficient mice with plasmin [52] or plasminogen (Figure 2(b)) rescues the low lung retention of tumor cells, bringing the numbers of survived cells close to those observed in wild-type mice.

Our recent unpublished findings also indicate that low metastatic prostate carcinoma cells, PC-lo/diss, which express little or no active UPA, induce lower levels of newly generated plasmin as compared with their high disseminating counterparts, PC-hi/diss, which express active uPA. Furthermore, we have also demonstrated recently that de novo generation of plasmin activity, occurring in response to tumor cell inoculations, depends on the host Plg- $\mathrm{R}_{\mathrm{KT}}$ as it was substantially diminished by anti Plg- $\mathrm{R}_{\mathrm{KT}} \mathrm{mAb} 7 \mathrm{H} 1$ (Casar et al., manuscript in preparation). It appears that the monitoring of plasmin generation and tumor cell retention in the lungs at $24 \mathrm{hr}$, that is, well before any immunological reactions are initiated because of histoincompatibility, provides an ideal model to analyze functionality of distinct molecules of the uPA/plasmin system expressed by human tumor cells versus host cells, such as murine vascular endothelium or inflammatory monocytes/macrophages. Finally, combined with the use of immunodeficient mice receiving human tumor cells or congenic hosts receiving murine tumor cells, our $24 \mathrm{hr}$ lung retention model allows to delineate initial contribution of individual components of the plasminogen system and de novo generated plasmin to longterm colonization which would be manifested several weeks after tumor cell inoculations.

\section{Specific Functions of In Vivo Generated Plasmin in the Tumor Microenvironment}

The elegant mechanism of uPA-mediated plasmin generation has been demonstrated to operate within the tumor environment. Hence, strong positive correlations exist between the levels of uPA expression in tumor cells and their migration, invasion, colonization, and metastasis, processes that are enhanced at least in part by tumor uPA-generated plasmin $[53,54]$. On the other hand, a specific role of host uPA in tumor development has been indicated by the retarded 


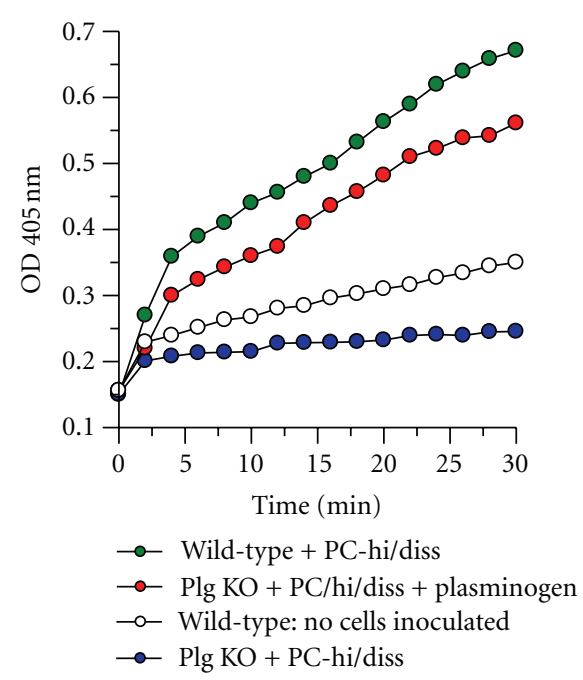

(a)

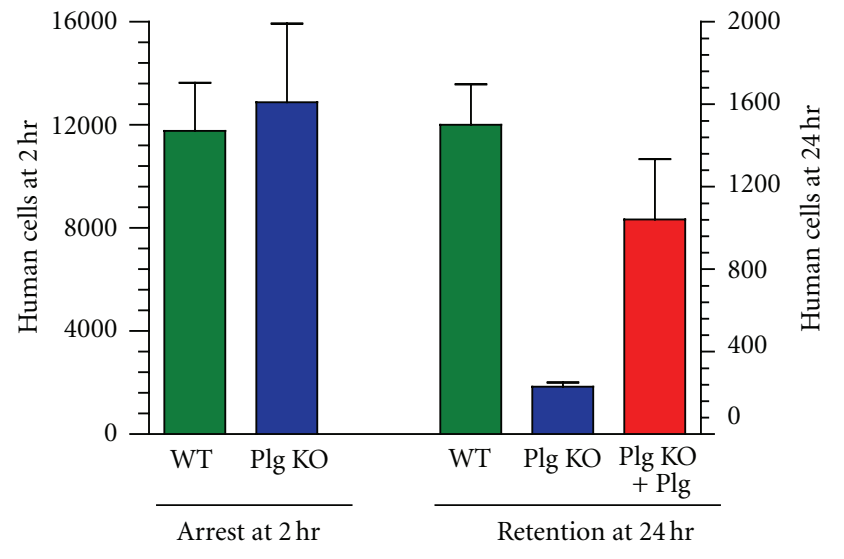

(b)

Figure 2: Analysis of plasma plasmin activity, tumor cell vascular arrest, and lung retention in mice after inoculation of human tumor cells. Prostate carcinoma PC-hi/diss cells were injected i.v. into wild-type mice (WT) or knock-out mice (KO) lacking plasminogen (Plg). Control wild-type mice did not receive any tumor cells. A group of Plg knock-out (KO) mice received purified plasminogen 1 hr after cell inoculations. Plasma was collected at $24 \mathrm{hr}$; lung tissue was collected at $2 \mathrm{hr}$ and $24 \mathrm{hr}$ after cell inoculations.

development and diminished vascularity of primary tumors originating from uPA-competent tumor cells implanted into uPA-deficient mice compared to implants in wild-type recipients [55]. The activity of host uPA also regulates inflammatory cell influx into primary tumors. For example, the levels of macrophage infiltration in mouse prostate tumors were significantly higher in uPA-competent hosts compared with uPA-deficient counterparts [56].

Comparative investigations performed in plasminogen null mice versus their plasminogen-expressing littermates allowed to more directly ascertain specific effects of plasmin in different aspects of normal physiology and cancer progression. Functional cooperation between host plasminogen and tumor uPA was shown to promote tumor growth and angiogenesis in the study employing implantation of uPAcompetent T241 fibrosarcoma cells into wild-type or plasminogen knock-out mice [57]. In the MMTV-PymT model of mammary gland carcinogenesis, the deficiency in plasminogen or uPA significantly decreased metastatic potential and levels of spontaneous lung metastases, indicating the in vivo role of plasmin generation $[58,59]$. The dependence of tumor growth on host plasminogen was demonstrated also in the foot pad model with Lewis lung carcinoma and T241 fibrosarcoma [60]. Surprisingly, no quantitative differences were observed in lung metastasis between plasminogen knock-out and control mice if the Lewis lung carcinoma cells were implanted subcutaneously [61], pointing to complexity of plasminogen functions, manifestation of which in cancer can depend on the site of tumor development. Plasminogen-deficient mice also manifest a significantly decreased angiogenic response to vascular endothelial growth factor (VEGF) or basic fibroblast growth factor (bFGF or FGF-2), which clearly indicates the importance of the plasmin system in angiogenesis in vivo [62]. The crossing of the blood-brain barrier by tumor cells also appears to depend on plasmin generation since plasminogen-deficient mice demonstrate lower levels of metastasis after intracarotid inoculations of melanoma cells compared to wild-type control [63]. An important physiological process as the recruitment of inflammatory cells also requires the availability of plasminogen, although the outcome of such influx critically depends on the model system. Thus, impaired accumulation of macrophages in the peritoneal cavity was observed in plasminogen knock-out mice $[64,65]$. In contrast, plasminogen suppressed the influx of tumor-infiltrating macrophages into fibrosarcoma tumors and inhibited tumor progression and angiogenesis [57].

In the following sections, we will discuss enzymatic functions of plasmin, focusing mainly on those studies, which have implicated plasmin in physiological processes in vivo and emphasizing a clear distinction between the suggestive nature of in vitro findings and conclusiveness of in vivo results demonstrating the proteolytic roles of plasmin in a live animal.

\subsection{Plasmin-Mediated Activation of Growth Factors and} Cytokines and Their Release from the ECM. By proteolytic processing and activation of nonenzymatic protein precursors and releasing them from the matrix, plasmin has been indirectly implicated in the downstream functional effects of several chemokines, hormones, and growth factors, including transforming growth factor $\beta$ (TGF- $\beta$ ), fibroblast growth factor-2 (FGF-2), and hepatocyte growth factor (HGF).

$\operatorname{TGF} \beta$ is a multifunctional cytokine that exerts diverse effects on virtually all cell types and plays a key role during embryo development and tissue homeostasis [66]. The TGF$\beta$ isoform, TGF- $\beta 1$, was one of the first cytokines shown to require proteolytic activation by plasmin to exert its 
biological functions [67]. Unlike most propeptides, the propeptide cleaved from the TGF proprotein has a high affinity for TGF- $\beta$ and assembles intracellularly into a noncovalent complex, composed of homodimers of the propeptide and the active TGF- $\beta$ molecule. After secretion from the cell, these large latent complexes covalently bind to various ECM molecules, including fibronectin, or to cell surface receptors [68]. The activation mechanism of latent TGF$\beta 1$ involves the proteolytic cleavage within the N-terminal glycopeptides, which causes a disruption of tertiary structure and noncovalent bonds and results in the release of active, mature TGF- $\beta 1$ [69]. Plasmin was initially shown to release TGF- $\beta 1$ from the pericellular matrix deposited by cultured fibroblasts and fibrosarcoma cells [70]. Pointing to a role in atherosclerosis, plasmin generated through uPAmediated conversion of exogenous plasminogen induced release of TFG- $\beta$ protein and TGF- $\beta$ activity in cultures of macrophages and foam cells [71]. Plasmin also releases TGF- $\beta$ from activated platelets during in vitro dissolution of blood clots [72]. In addition, the ability of cultured alveolar macrophages to generate plasmin suggested its involvement in TGF- $\beta 1$ activation in the mice after lung injury [73].

During the last 2 decades of investigations, many mechanisms of TGF- $\beta$ activation have been described in vitro and comprehensively summarized in several reviews $[68,74]$. However, a gap remains in the demonstration and understanding of TGF- $\beta$ activation in vivo. Since TGF- $\beta$ activation is the rate-limiting step in TGF- $\beta$ bioavailability, it is surprising that the functional role of plasmin has not been resolved by using mice genetically devoid of critical members of the PA system. Thus, neither plasminogen-deficient mice nor uPA or tPA knockouts [75-78] exhibit phenotypic similarities with TGF- $\beta$ null mice [68], casting some doubt on all the in vitro data extolling the role of plasmin-mediated activation of TGF- $\beta$. Thus far, the most compelling, albeit indirect, result indicating a contribution of plasmin to in vivo activation of TGF- $\beta$ was obtained in the study where the plasmin inhibitor, aprotinin, inhibited generation of TGF- $\beta 1$ in mice with IL-13-induced lung fibrosis [79].

The 1990 demonstration that plasmin can liberate FGF-2 [80] represents another early example of protease-mediated release of a growth factor from the ECM. FGF-2 is a potent growth factor, which plays an important role in various cell functions, including cell proliferation, and manifests its activity in a number of physiological processes, including tumor angiogenesis $[81,82]$. Similar to studies of TGF- $\beta$ activation, the plasmin-mediated FGF-2 release from pericellular matrices has been shown mainly in vitro. Thus, the release of FGF-2 by plasmin and other proteolytic enzymes was initially demonstrated in endothelial cell cultures [83], suggesting a mechanism for induction of angiogenesis. In an ex vivo system, the release of FGF-2 coordinated with FGF2-dependent induction of smooth muscle cell proliferation was shown in organ cultures employing vein segments [84]. Importantly, this study specifically addressed the contribution of plasmin activity to FGF-2 liberation and FGF2 -mediated cell proliferation. Supporting the notion that plasmin activity indeed released matrix-bound FGF-2, the inhibitory effects of the specific plasmin inhibitor, NALME, or the neutralizing anti-uPA antibody on smooth muscle cell proliferation were reversed by exogenous FGF-2 added to inhibitor-containing cultures [84]. FGF-2 was shown also to increase secretion of uPA by cultured endothelial cells [85], suggesting a putative in vivo feedback mechanism, whereby uPA-generated plasmin would induce proteolytic degradation of the ECM, release more FGF-2, and thus indirectly mediate FGF-2-dependent endothelial cell migration and angiogenesis.

The first experimental evidence that plasmin can release FGF-2 in vivo was provided in the chick embryo model where exogenous human uPA or uPA-overexpressing human tumor cells induced neovascularization which was attenuated by anti-FGF-2 antibody [86]. However, the data from our laboratory demonstrate that in a collagenous matrix environment, the release of FGF-2 is facilitated by MMP-9 delivered by inflammatory neutrophils [87]. Reconciling an apparent discrepancy of plasmin-versus MMP-9-mediated release of angiogenic FGF-2, some recent data suggest cooperation between plasmin and MMP-9 during physiologic and tumorinduced angiogenesis. Thus, plasmin incorporated in low nanomolar concentrations into collagen rafts grafted onto the CAM of chick embryos induces a dose-dependent angiogenic response susceptible to aprotinin inhibition (Ewa Zajac, unpublished observations). Exogenous plasmin also induces the angiogenic potential of low metastatic and low angiogenic prostate carcinoma cells, PC-lo/diss, expressing only single-chain nonactive uPA. While the mechanisms of plasmin-induced angiogenesis in this model system are still under investigation, additional experiments have indicated that angiogenesis induced either by exogenously added purified MMP-9 or endogenously supplied neutrophil MMP-9 is highly sensitive to low concentrations of aprotinin. These results demonstrate that the activity of de novo generated plasmin somehow overlaps or converges with the angiogenic functions of MMP-9, suggesting close in vivo relationships between these two proteolytic systems, and highlighting functional cooperation between PA/plasmin and MMP-9 in tumor angiogenesis. Consistent with this suggestion, simultaneous downregulation of uPA, uPAR, and MMP-9 significantly inhibited angiogenesis induced by glioma cells in an intracranial tumor model in nude mice [88].

A kringle domain-containing glycoprotein, HGF (or scatter factor), is another growth factor that requires activation and release from the ECM to exert its biological activity through the binding to its cell surface receptor, c-met [89]. HGF is produced as a latent, single-chain precursor, which is tightly bound to heparan sulfate proteoglycans. Internal proteolytic cleavage of the HGF precursor generates the active disulfide-linker dimer that can be released from the ECM and bind the c-met on adjacent target cells. Plasmindependent mechanism of HGF release was suggested in a lung injury model, where the plasmin inhibitor, tranexamic acid, blocked release of the factor in the bleomycin-treated mice [90]. This suggestion was later validated in the in vitro study, where mouse lung fibroblasts were shown to functionally activate and release ECM-bound HGF in a plasminogen-dependent fashion [91]. 
Plasmin has been also shown to proteolytically process chromogranin A ( $\mathrm{CgA})$, the neuronal prohormone stored in catecholamine vesicles [92]. Since plasmin is present in the local environment of chromaffin cells, it was suggested that it can selectively cleave CgA and generate a bioactive fragment inhibiting nicotinic-mediated catecholamine release. Data from plasminogen-deficient mice have also provided the evidence that plasmin is a major in vivo protease that regulates the processing of hormones derived from the proopiomelanocortin precursor. Thus, a deficiency of plasminogen reduces processing of $\beta$-endorphin and $\alpha$-melanocyte stimulating hormone, thereby causing behavioral abnormalities in response to stress [93]. Recently another neuronal factor, namely brain-derived neurotrophic factor (BDNF), was demonstrated to be processed and activated specifically by plasmin. Being secreted as an unprocessed proform, this neurotrophin undergoes proteolytic cleavage in the pericellular environment by plasmin, which results in generation of an active form of BDNF capable of stimulating neurite outgrowth [94].

Plasmin has also been shown to induce expression of Cyr61 [95], the angiogenic growth-like factor, which acts as an ECM-associated signaling molecule and regulates proliferation and migration of fibroblasts during wound repair [96]. A pathway was suggested for plasmin-mediated promotion of fibroblast proliferation, which involves two independent steps. In the first step, Cyr61 expression is induced via plasmin-mediated PAR1 activation, and then, in the second step, plasmin releases Cyr61, originally deposited in the extracellular matrix, making it ready to act on cells [97]. In addition to overall release of Cyr61 from the matrix deposited by fibroblasts, the authors also showed that Cyr61 itself was a plasmin target since only plasmin-cleaved recombinant Cyr61 was functionally competent to induce cell proliferation. Therefore, this model system provides an example where plasmin-mediated release of a growth factor was accompanied by the direct demonstration of its functional activation.

Recently, Kapoor with coauthors demonstrated that plasmin can activate the cytokine function of the extracellular synthetase, TrpRS, which becomes a potent angiostatic factor acting through the vascular endothelial-cadherin (VEcadherin) receptor and Akt signaling pathway [98]. In vitro cleavage of recombinant TrpRS by plasmin resulting in production of low molecular weight fragments suggests that in vivo plasmin localized to the surface of endothelial cells, for example, through plasminogen receptors such as S100A10, could process secreted TrpRS and generate angiostatic active fragments. Since TrpRS is secreted by endothelial cells, this scenario can also provide a possible mechanism for negative feedback regulation of tumor angiogenesis.

5.2. Plasmin-Mediated Activation of MMP Zymogens. Indirectly, through its ability to proteolytically activate in vitro many matrix-remodeling proteases, plasmin has been implicated in various aspects of tissue remodeling, including tumor angiogenesis and cancer progression [2, 99, 100]. In cell-free systems and cell cultures, plasmin was shown to activate zymogens of many matrix metalloproteinases (MMPs), including MMP-1 [101-103], MMP-2 [104, 105], MMP-3 [106], MMP-9 [104, 107], MMP-13 [108], and MMP-14 [109]. Further solidifying the notion that plasmin has such a broad-range substrate specificity that renders it a nonspecific proMMP activator, cultures of macrophages isolated from uPA deficient mice and supplemented with purified plasminogen clearly demonstrated accumulation of activated forms for MMP-3, MMP-9, MMP-12, and MMP-13 in the conditioned medium [110].

Activation of proMMP-1, the zymogen of a potent interstitial collagenase, represents a well-documented case for plasmin functioning as an MMP-activating enzyme. In cultures of dermal fibroblasts and keratinocytes, producing proMMP-1, plasmin was shown to induce rapid activation of the proenzyme which occurred through a uPA pathway and was facilitated by exogenously added plasminogen [111]. Strict dependency of proMMP-1 activation on plasmin activity, generated on cell surfaces via plasminogen conversion, was demonstrated in alveolar epithelial cell cultures [112]. Plasmin-activated MMP-1 then can perform specific collagenase functions manifested in collagen matrix modifications, for example, contraction of collagen matrices [113].

In HT-1080 fibrosarcoma cell cultures, plasmin was shown to activate two gelatinases, MMP-2 and MMP-9, activation of which required plasminogen conversion through the surface bound uPA [104]. Activation of MMP2 by plasmin was demonstrated to require the association of MMP-2 zymogen with the membrane-type MMP, MMP14, but surprisingly, the catalytic activity of MMP-14 was not essential [105]. Though exact mechanisms of proMMP-2 and proMMP-9 activation by plasmin were not revealed in these studies, the processing of both zymogens was documented by zymography and the resulting enzymatic activity was confirmed biochemically by cleavage of collagen IV and fibrin, providing a nice example of cooperation between the serine protease system and MMP system in regulation of gelatinase functions.

Gradual activation of proMMP-9 was observed in cultures of thioglycollate-induced peritoneal macrophages in the presence of exogenously added plasminogen and in wildtype mice during thioglycollate-induced peritonitis, but it was impaired in plasminogen-deficient mice [65]. Plasmindependent activation of proMMP-9 was also demonstrated in comparative analysis of ex vivo cultures of vascular explants from wild-type versus plasminogen knock-out mice [114]. The uPA/plasmin system was functionally implicated in cell migration dependent on active MMP-9; however putative activation of proMMP-9 by plasmin was not manifested by pronounced accumulation of any activated species of MMP-9 in this study [115]. An indirect mechanism of MMP-9 activation was demonstrated in breast carcinoma cell cultures, where plasmin did not directly activate the MMP-9 zymogen but first activated the stromelysin MMP-3, which in turn acted as a potent activator of proMMP-9 [106]. Together, these studies indicate that conversion of plasmin and MMP proteolytic systems is complex and may include several intermediate components. 
Functional involvement of the uPA/plasmin cascade in activation of MMP-13, collagenase-3, was demonstrated in our investigation of the pro-angiogenic capacity of MMP-13 [116]. In this study we demonstrated that during growth factor-induced angiogenesis, inflammatory monocytes/ macrophages deliver proMMP-13 to collagen-enriched matrices, where this zymogen is activated and then functions in $\mathrm{uPA} /$ plasmin-dependent manner. In vitro, the MMP-13 proenzyme is rapidly and efficiently activated through the uPA/plasminogen/plasmin cascade into a collagenase capable of cleaving native but not the mutant collagenase-resistant collagen. In vivo, purified MMP-13 elicited an angiogenic response at nanomolar concentrations, comparable with angiogenic growth factors FGF-2 and VEGF. Angiogenic responses induced either by FGF-2/VEGF or MMP-13 were abrogated by the plasmin inhibitor aprotinin, not only indicating that plasmin-activated MMP-13 functions as an angiogenic factor in vivo but once again pointing to a functional cooperation between two distinct matrix-degrading protease systems.

Despite the fact that plasmin cleavage was well documented in vitro for several MMPs, including MMP-1, MMP-3, MMP-9, MMP-12, and MMP-13, the majority of studies did not confirm that the putative active MMPs had actual enzymatic activity. In this regard, we showed that under physiological conditions plasmin is not a direct activator of MMP-9 [106], and recently we also demonstrated that although plasmin is capable of processing $92-\mathrm{kDa}$ MMP-9 zymogen in vitro to lower-molecular-weight forms, it does not generate enzymatically active MMP-9 capable of cleaving specific peptides or gelatin. Furthermore, in vivo studies from other laboratories employing mice deficient in plasminogen or other components of the plasmin-generating system failed to clearly demonstrate that plasmin-mediated activation of distinct MMPs indeed occurred in live animals during matrix remodeling even when the lack of plasmin functionally interfered with MMP-dependent processes. Usually the impairment in MMP-mediated functions has been liberally attributed to the lack of plasmin-mediated activation and therefore, lack of enzymatic activity of the corresponding MMPs. Alternatively, when plasmin-dependent activation of MMPs has been clearly documented biochemically in tissues or body fluids, physiological consequences of the MMP activity missing in plasmin-deficient mice might not have been followed up.

Importance of plasmin in the regulation of MMPmediated functions in vivo has been demonstrated for several MMPs in studies involving mice deficient in plasmin generation. These studies instigated a general conclusion that plasmin is involved in MMP-dependent matrix proteolysis and cell functions requiring matrix remodeling. Thus, mice lacking either plasminogen or both plasminogen activators, uPA and tPA, manifest significantly delayed wound healing kinetics as compared to wild-type mice and show strict dependency of residual wound healing on the activity of unidentified, GM6001-sensitive MMPs [117]. Several MMPs are expressed in the leading-edge keratinocytes in a skin wound, including MMP-2, MMP-3, MMP-9, and MMP-13.
However functional overlap of plasmin and MMP systems in wound healing was indicated thus far for MMP-13 in the double knock-out model [118]. In contrast, mice deficient in both MMP-2 and plasminogen manifested no difference in wound healing compared with singular plasminogen knockouts [119], likely indicating that, in contrast to in vitro results, plasmin is either not responsible for MMP-2 activation in vivo or that MMP-2 activity is dispensable in this model system.

The synergy between a plasminogen cascade and MMP9 was also indicated in the mouse model of autoimmune disease where delayed blister formation in plasminogendeficient or uPA/tPA knockouts was restored by applications of the active form of MMP-9 [107]. Importantly, this rescue of a plasminogen-dependent phenotype was not achieved with the MMP-9 zymogen, strongly implicating plasmin in functional activation of MMP-9 in vivo.

Functional overlap between the two matrix-degrading proteolytic systems was definitively demonstrated in the hematopoietic system, where stem cells were shown to require plasmin activity to enter cell cycle and initiate multilineage differentiation since genetic deficiency in plasminogen severely impaired the recovery of the hematopoietic system after chemical ablation [120]. Mechanistically, plasmin activity was linked to the activation of MMP-9 and MMP9-induced release of Kit ligand, the factor that earlier was shown to be obligatory for immobilization of hematopoietic stem/progenitor cells (HSPCs) from bone marrow in response to myelosuppression [121]. The specific mechanisms whereby the plasmin fibrinolytic and MMP pathways control each other and cooperatively regulate hematopoiesis, hematopoietic regeneration, and angiogenesis driven by myeloid cells are described in detail in reviews by Heissig and coauthors $[122,123]$. An important clinical implication of functional activation of MMP-9 by plasmin was recently demonstrated by inhibitory effects of the active-site-directed inhibitor of plasmin, YO-2, on MMP-9-dependent growth of T-cell lymphoma and recruitment of tumor-promoting myeloid cells to the sites of tumor development [124].

\subsection{Plasmin-Mediated Modifications of Extracellular Matrix} Proteins. A broad range of substrates has been indicated by the ability of plasmin to cleave many purified proteins in vitro [100]. However, relatively few studies directly linked de novo generated plasmin activity with proteolysis of extracellular matrix proteins in tissues or direct cleavage of specific proteins in the matrix deposited by cells in culture.

More than 30 years ago, Liotta and coauthors demonstrated in vitro that plasmin could degrade several purified basement membrane proteins, including laminin and fibronectin, and also degrade native laminin from the amnion basement membrane [125]. Later, a specific form of laminin, laminin 5, found in the epithelial basement membrane and deposited in tumor-produced matrix, was shown to be susceptible to tPA-activated plasmin [126]. In turn, binding of tPA and plasminogen to laminin 5 results in a dramatic, 30-fold enhancement of plasminogen activation [127]. In the nervous system, the positive contribution 
of laminin-1 proteolysis by plasmin was suggested in a neuritogenesis study, in which plasmin activity generated from the exogenously added plasminogen-enhanced development of neurites and induced laminin-1 cleavage in vitro [128]. However, the cleavage of the specific laminin form, laminin $\gamma 1$, by plasmin-mediated proteolysis in the central nervous system in vivo, was shown to cause neuronal degeneration via activation of caspase-3 [129]. This neuronal degeneration due to laminin degradation was not observed in plasminogen-deficient or tPA-deficient mice and was prevented by the use of a plasmin inhibitor in plasminogencompetent mice, confirming that plasmin was involved in the observed effects in vivo and indicating crucial importance of regulating the generation of plasmin and its activity [130132].

When subjected to limited proteolytic digestion, fibronectin is cleaved only in specific regions, where the protein is believed to be nonfolded and therefore unprotected from protease attack [133]. Most of fibronectin activities have been ascribed to an insoluble form that exists as part of the ECM, where fibronectin matrix assembly is a tightly regulated cell-mediated process. In fibroblast cultures, plasmin-induced degradation of matrix-bound fibronectin was associated with cell apoptosis [134]. Despite the fact that fibronectin can be digested in vitro by multiple proteases, including plasmin, the role of proteolytically modified fibronectin in vivo remains underexplored, especially in cancer-related systems. Under normal physiological conditions in vivo, adipocyte differentiation was shown to require plasmin-mediated degradation of the fibronectinrich preadipocyte stromal matrix as it was abolished in plasminogen-deficient mice [135].

Plasmin cleavage of fibronectin and laminin in vivo was demonstrated in wild-type mice during bone marrow remodeling and recovery of hematopoietic system after 5-fluorouracil treatment [136]. In contrast, plasminogen knock-out mice manifested substantially larger deposits of fibronectin and higher expression of laminin in bone marrow, indicating that loss of plasmin impaired degradation of these ECM proteins. This conclusion was supported by immunoblotting analysis, which demonstrated less lowmolecular-weight fragments of fibronectin and laminin in bone marrow plasma samples from plasminogen-deficient mice as compared to wild-type counterparts. However, it was not clarified whether these cleavage products of fibronectin originated from nonsoluble ECM of bone marrow or directly related to soluble plasma fibronectin, one of the most abundant adhesion proteins in the blood [137].

In our CAM model of spontaneous metastasis, inhibition of uPA-generated plasmin with the serine protease inhibitor aprotinin resulted in accumulation of fibronectin at the tumor border and within primary tumors, suggesting that fibronectin undergoes plasmin-mediated proteolysis in nontreated control tumors [28]. Since inhibition of plasmin generation or abrogation of plasmin activity was concomitant with significantly diminished tumor cell escape from primary tumors and reduced stromal invasion, we attempted to directly link cellular uPA-generated plasmin to plasminexecuted fibronectin proteolysis to enhanced migration of tumor cells on the plasmin-modified fibronectin. Thus, when presented with fibronectin cleaved by plasmin, tumor cells increased their migration by 2.5 -fold over the levels induced by nontreated fibronectin. Combined with the demonstration that escape from primary tumors and stromal invasion of active uPA-expressing prostate cancer cells were inhibited by function-blocking antibody against $\alpha 5$ integrin, these findings suggested a motility-involving mechanism, whereby tumor cell uPA-generated plasmin cleaves tumorassociated fibronectin and enhances $\alpha 5 \beta 1$ integrin-mediated cell motility of tumor cells in vivo [28].

A negative feedback mechanism for abrogation of plasmin generation was proposed whereby the ECM protein vitronectin was shown to be specifically cleaved by plasmin in vitro, significantly reducing the ability of the cleaved vitronectin to bind PAI-1, thus making PAI-1 available to inhibit plasmin-generating uPA [138]. In addition, in vitro cleavage of vitronectin by plasmin can diminish uPARdependent cell adhesion and therefore provide a mechanism for regulation of cell motility [139]. Noteworthy, neither of these early demonstrations of vitronectin cleavage by plasmin was followed up to demonstrate that such cleavage occurs and has a functional importance in vivo.

Tenascin $\mathrm{C}$ represents another matrix protein that was shown to be cleaved by plasmin in vitro, converting it from a non-adhesive to adhesive substrate for $\mathrm{T}$ lymphocytes [140]. In tumors, tenascin C is produced by both tumorassociated fibroblasts, cancer cells, and cancer stem-like cells and interacts with various membrane receptors and ECM proteins to promote metastatic colonization [141]. Furthermore, stromal tenascin $\mathrm{C}$ was shown to be produced by cells expressing the plasminogen receptor S100A4 [141], suggesting that these cells can also facilitate plasmin production at the sites of metastatic colonization. Recently, tenascin $\mathrm{C}$ has also been found in stem cell niches, where along with other matrix components it supports the survival of breast cancer cells responsible for lung metastases [142]. Therefore, plasmin-mediated cleavage of tenascin C inducing its adhesive functions may represent a putative proteolytic mechanism for regulation of the biochemical and functional properties of this important matrix protein in stem cell niches.

Recently, osteopontin has been shown to be a novel ECM substrate for plasmin [143]. Osteopontin, a secreted noncollagenous, sialic-acid-rich, chemokine-like protein, plays a crucial role in determining the oncogenic potential of various cancers. Osteopontin has a protease-hypersensitive site that separates the integrin- and CD44-binding domains. Osteopontin has been previously shown to be cleaved in vitro by thrombin and MMPs, which modulate osteopontin functions and enhance integrin-binding properties in cell function assays $[144,145]$. Plasmin-mediated cleavage of osteopontin, occurring at multiple sites near integrinbinding motifs, also results in increase of cell adhesion mediated by $\alpha \mathrm{v} \beta 3$ or $\alpha 5 \beta 1$ integrins [143]. Therefore, plasmin can be a potent regulator of osteopontin functions at the sites of primary tumor development as well as at the secondary sites, for example, in metastatic niches, where osteopontin might be an important constituent. Noteworthy, 
osteopontin is a key component of hematopoietic niches, where it regulates physical location and proliferation of hematopoietic stem cells [146]. It might also be noted that plasmin cleavage of osteopontin enchancing integrinmediated adhesion contrasts plasmin cleavage of fibronectin enhancing integrin-mediated cell migration [28].

In conclusion of this section, it is worth to mention that the notion that plasmin executes cleavage of a large number of distinct ECM proteins in vivo in live animals appears not to be well substantiated by rigorous experimental evidence. Studies performed in plasminogen-deficient mice or mice lacking uPA and/or tPA have provided such evidence thus far for laminin and fibronectin, conclusively demonstrating the biological significance of plasmin in physiological processes critically dependent on limited proteolysis of these ECM molecules. The recent generation of transgenic mice, expressing two alleles of plasminogen gene with an S743A inactivating mutation in the latent active site, allows for selective elimination of all in vivo proteolytic activity of plasmin while preserving all effects associated with the presence of plasminogen and its binding to plasminogenreceptor-like molecules [147], making this newly developed Plg ${ }^{S 743 A / S 743 A}$ mouse line especially valuable for cancer progression studies.

\section{Cell Surface Remodeling by In Vivo Generated Plasmin}

The above-reviewed evidence strongly implicates plasmin as an extracellular proteinase that modulates the tumor microenvironment by cleaving proteinaceous substrates, although they often have been suggested by in vitro cleavage products rather than conclusively demonstrated as plasmincleaved proteins in vivo within tumor tissues. However, several studies illuminate another side of plasmin functionality, namely, its ability to cleave specific membraneanchored receptors and transmembrane proteins and to attenuate or trigger outside-in signaling cascades through distinct signaling partners or through direct activation of signal transduction initiated by the cytoplasmic domain of a membrane-retained cleaved fragment.

\subsection{Plasmin Processing and Inactivation of Cell Surface Recep-} tors. Four known protease-activated receptors (PARs) represent a unique class of G-protein-coupled receptors that play critical roles in thrombosis, inflammation, vascular biology and cancer [148, 149]. Among PARs, proteolytic cleavage of PAR1 by thrombin represents the first example of signal transduction through a transmembrane receptor, proteolytically modified by serine proteases [150]. Thrombininduced activation of PAR1 involves cleavage of the fulllength molecule at the R41-S42 site and release of an aminoterminal fragment, resulting in a reduction of molecular weight of the membrane-retained fragment [151]. This cleavage generates a new amino terminus that serves as a tethered ligand domain, which binds to the second loop of the cleaved receptor, resulting in the initiation of signal transduction. Thrombin-induced activation of PARs and
PAR signaling has been extensively investigated in studies on hemostasis, blood vessel development, and various cancerrelated processes [148, 152-156].

In contrast to thrombin, plasmin-mediated cleavage of PAR1 and its putative implications to cell physiology have not been followed up extensively and precise downstream signaling induced by plasmin-cleaved PAR1 has not been investigated in detail in cancer biology, possibly because plasmin was initially reported to desensitize PAR1 due to the cleavage within the tethered ligand [157]. MALDI-TOF mass spectrometry of fragments generated by plasmin proteolysis of the exodomain of recombinant PARs also predicted that plasmin would inactivate PAR1 [158]. However, by cleaving PAR1 at the R41 thrombin cleavage site, plasmin can generate an activated exodomain without desensitization of $\mathrm{Ca}^{2+}$ signaling [157], suggesting that plasmin cleavage of PAR1 can produce dual, activating and attenuating, effects on PAR1 signaling. Furthermore, aprotinin has been demonstrated to inhibit PAR1-specific functions in vitro and also during cardiothoracic surgery [159], indicating that plasmin might be involved in PAR1 activation. Consistent with an activating role of plasmin cleavage of PAR1, uPA-mediated conversion of plasminogen into plasmin and plasmin-mediated cleavage of PAR1 have been shown to prevent apoptosis induced in monocytic cells by TNF $\alpha$ or cycloheximdie [160]. Functional involvement of PAR1 in mediating antiapoptotic signals was confirmed by the use of specific anti-PAR1 antibodies. Moreover, apoptosis resistance required the involvement of exogenous plasminogen with an intact protease domain for further proteolytic activity and the presence of unoccupied lysine binding sites within the kringle domains for binding to cell surface plasminogen receptors [160]. Overall, these findings suggest that in specific in vivo locales enriched in active uPA, such as the tumor microenvironment, newly generated plasmin activity may regulate cell death through induction of PAR1 survival signaling during crosstalk between tumor cells and peripheral blood monocytes.

Depending on tissue environment, PAR1 activation and PAR1-induced signaling can be elicited not only by thrombin or plasmin, but by a member of a different class of proteases. Thus in certain tumor-stromal microenvironments, MMP1 has been shown to function as a protease agonist of PAR1, directly cleaving the receptor and generating PAR1dependent cell signaling and migration [161]. Moreover, MMP-1 activity was shown to derive from fibroblasts and not from the breast cancer cells, strengthening the importance of crosstalk and cooperation of host and tumor cells during cancer progression. Since PAR1 cleavage by thrombin and MMP1 appears to occur at the identical site, namely, between R41 and S42 residues, it is likely that PAR1 cleavage by any of these proteases would induce identical signaling cascades. Thus, both proteases were shown to induce PAR1-dependent $\mathrm{Ca}^{2+}$ signaling [148, 161]. However, signaling by PAR1associated partners has not been compared extensively, leaving a possibility that cleavage by thrombin, plasmin or MMP-1, may induce unique signaling cascades differentially regulating cell functions in a specific, microenvironmentdependent manner. Consistent with this notion, MMP-1mediated cleavage of PAR1 in breast cancer cells was shown 
to activate Akt survival pathway, attenuation of which by respective inhibitors of MMP-1 activity and PAR1 signaling resulted in the induction of cell apoptosis and inhibition of lung metastasis [162]. Therefore, it is plausible to link the redundancy in PAR1 agonists to the possibility that cell locale enriched in proteolytic enzymes belonging to one or another class of proteases would dictate the specific choice of the receptor-activating protease(s).

Investigations of the mechanisms underlying the impairment of hematopoietic recovery in UPA and tPA knock-out mice indicated that, in addition to activation of MMP-9 and induction of MMP-9-mediated release of kit ligand [120], plasmin can be involved in an additional mechanisms of HSC mobilization. Namely, plasmin was shown to proteolytically cleave and functionally inactivate UPAR in HSPCs, enabling them to detach from bone marrow matrix and egress into the circulation [163]. Being a GPI-anchored molecule, uPAR signals through other accessory molecules such as $\alpha 4 \beta 1$ integrin but only if uPAR is intact, and therefore plasmin cleavage can functionally inactivate UPAR and abrogate uPAR-mediated signaling. Cleavage of uPAR, indicated in this study by a reduced binding of antibodies recognizing only intact uPAR, represents an example of proteolytic modification of a plasma-membrane-associated molecule, modification of which by plasmin does not directly induce downstream signaling cascades.

6.2. Plasmin Cleavage of Neuronal Receptors. In the central nervous system, plasmin has been shown to cleave $N$-methylD-aspartate (NMDA) receptors, increasing their functional responses [164]. NMDA receptors are transmembrane glutamate receptors responsible for neurotransmission and synaptic plasticity. The functional NMDA receptor is a heterotetramer consisting of two NR1 subunits and two NR2 subunits, which bind specific ligands: the coagonist glycine binds to the NR1 subunit, whereas NR2 subunit binds the neurotransmitter glutamate. Both NR subunits have a modular design, and each subunit has an extracellular module, a complex transmembrane domain, and an extensive cytoplasmic domain. The NR2 subunit controls the electrophysiological properties of the NMDA receptor and is represented by four distinct isoforms, which are expressed differentially in various cell types. The intracellular C-terminal domains of individual NR2 isoforms can interact with different sets of signaling messengers. The NMDA receptors serve as $\mathrm{Ca}^{2+}$ cation channels that can be blocked by several divalent cations, including $\mathrm{Mg}^{2+}$ and $\mathrm{Zn}^{2+}[165$, 166].

By proteolytically cleaving the NR2A subunit aminoterminal domain and removing the $\mathrm{Zn}^{2+}$ binding site, plasmin was shown to prevent $\mathrm{Zn}^{2+}$-mediated inhibition of NR2A-containing NDMA receptors. Plasmin cleavage of fulllength $180 \mathrm{kDa}$ NR2A subunit occurs at $\mathrm{Lys}^{317}$, producing a $40 \mathrm{kDa}$ N-terminal fragment and leaving a truncated $140 \mathrm{kDa}$ transmembrane C-terminal fragment. Noteworthy, plasmin-mediated relief of the $\mathrm{Zn}^{2+}$ inhibition via removal of the $\mathrm{Zn}^{2+}$ binding site increases responses of NMDA receptors in neurons independently of a plasmin activation of PAR1 [164]. Since NMDA receptors have cytoplasmic domains, harboring residues that can be modified by protein kinases and phosphatases, as well as residues that can interact with various structural, adaptor, and scaffolding proteins, it is possible that plasmin-activated NMDA receptor could induce antiapoptotic pathways to play a critical role in regulation of neuronal cell death.

6.3. Plasmin Cleavage of Cell Surface CDCP1 and Its Functional Activation. Recently, we have presented direct evidence that plasmin cleavage of a single-pass transmembrane molecule can trigger its functional activation through the phosphorylation signaling initiated at the cytoplasmic domain of the membrane-retained fragment [52]. Specifically, we have demonstrated that plasmin executes in vivo cleavage of a cancer-related molecule, CUB domaincontaining protein 1 (CDCP1), and showed that CDCP1 cleavage leads to outside-in signaling involving activation of Akt and suppression of PARP1-induced cell apoptosis. This signaling cascade ultimately regulates the survival potential of tumor cells in the late stages of the metastatic cascade, namely, during extravasation and early tissue colonization [52].

$\mathrm{CDCP} 1$ is a transmembrane glycoprotein highly expressed in a number of malignancies, including cancer of colon, breast, prostate, stomach, lung, kidney, pancreas, and skin [167-171], making CDCP1 an attractive prognostic marker and putative therapeutic target. Functional importance of CDCP1 in cancer is supported by experimental findings demonstrating that CDCP1-positive tumor cells have advantage in metastasis xenograft model systems of lung and gastric cancers $[172,173]$. Our unpublished findings in mouse models of human prostate cancer also indicate that high levels of CDCP1 in prostate carcinoma PChi/diss cells positively correlate with high levels of secondary organ colonization compared to the cell counterparts where expression of CDCP1 was reduced by RNA interference. Confirming the notion that CDCP1 is a prometastatic molecule, de novo expression of CDCP1 in HeLa and HEK cell lines, both completely devoid of CDCP1, dramatically increased their potential to colonize internal organs of immunodeficient mice and chick embryos [52, 174]. Furthermore, our specific anti-CDCP1 mAbs, uniquely generated by a process of subtractive immunization [175], significantly reduced colonization and spontaneous dissemination of prostate carcinoma PC-hi/diss cells naturally expressing CDCP1 in the chick embryo metastasis models [174].

The full-length CDCP1 is $135 \mathrm{kDa}$ molecule containing the extracellular $\mathrm{N}$-terminus with 3 CUB domains, the single-pass transmembrane domain, and the C-terminal domain with several tyrosine residues [175]. Phosphorylation of C-terminal tyrosines by Src family kinases was shown to lead to docking of PKC $\delta$ and its Src-dependent phosphorylation [176]. This PKC $\delta$ signal transduction facilitates anoikis resistance of human tumor cells [172], indicating that CDCP1 can act as an important cell surface signal transducer and regulator of multiple cell functions. In search 
of the triggers of such outside-in signal transduction, we explored the possibility whether cleavage of the CDCP1 molecule, previously demonstrated in cell cultures in vitro, would be responsible for initiation of CDCP1 phosphorylation and downstream signaling cascades in vivo.

CDCP1 is resistant to proteolytic attacks of MMP-1, MMP-3, and MMP-9. However, several serine proteases, including trypsin, plasmin, and matriptase, can cleave CDCP1 at R368 and K369, generating the $70 \mathrm{kDa}$ membrane-retained fragment $[52,177]$. In vitro studies confirmed that CDCP1 cleavage was associated with phosphorylation of the $70 \mathrm{kDa}$ fragment and $\mathrm{Src}$ and $\mathrm{PKC} \delta$ recruitment specifically to the cleaved CDCP1 fragment [177]. We further demonstrated that both cleavage by serine proteases and cleavage-induced phosphorylation of cleaved CDCP1 can be completely blocked by the serine protease inhibitor aprotinin or by genetic mutation of the cleavage site. Moreover, we confirmed that our function-blocking anti-CDCP1 mAbs completely prevent proteolytic cleavage of CDCP1, suggesting the in vivo mechanism for previously demonstrated inhibitory effects of these antibodies in metastasis [174]. In agreement with our expectations, anti-CDCP1 mAbs completely inhibited CDCP1 cleavage in vivo, concomitant with significant inhibition of experimental and spontaneous metastasis of PC-hi/diss cells.

The availability of our high-affinity anti-CDCP1 mAbs allowed us to analyze for the first-time signal transduction elicited in vivo by CDCP1 cleavage and establish a signaling cascade required for high levels of tumor cell dissemination. This cascade operating in vivo during tumor cell extravasation from the vasculature involves sequential docking of Src, Src-mediated phosphorylation of CDCP1 fragment at Tyr734 and docking of PKC $\delta$ phosphorylated in phosphoSrc/phosphoCDCP1-dependent manner. By using the inhibitor of Src activation, dasatinib, we also clarified that both active and nonactive Src can bind to the cleaved CDCP1, but phosphorylation of CDCP1 occurs only if the docked Src has kinase activity.

Specific processing of cell surface CDCP1 by an extracellular serine protease is a prerequisite for CDCP1-induced signaling in vivo and CDCP1-mediated survival of cancer cells during metastasis. The in vivo cleavage of CDCP1 triggers $\mathrm{Src} / \mathrm{PKC} \delta$ signal transduction, involving downstream activation of Akt and suppression of caspase-induced PARP1 activation. This multistep signaling cascade ultimately increases tumor cell survival and sustain high levels of tumor colonization. Preventing the in vivo cleavage of CDCP1 with unique anti-CDCP1 antibodies, serine protease inhibitors or genetic modulation of the cleavage site in the CDCP1 molecule completely abrogated survival signaling and induced PARP1-mediated apoptosis, resulting in a substantial inhibition of metastatic colonization. Finally, by using our lung retention model (Figure 1), we demonstrated complete lack of CDCP1 cleavage in plasminogen knock-out mice, therefore for the first time identifying plasmin as the major serine protease responsible for cleavage of CDCP1 in a live animal. This lack of CDCP1 cleavage in plasminogendeficient mice was accompanied by reduction in tumor cell survival, which, importantly, could be both rescued by in vivo supplied purified plasmin [52] or plasminogen (Figure 2(b)), confirming that plasmin is the crucial serine protease executing cleavage of CDCP1 in vivo. Moreover, in this tumor cell in vivo setting, we confirmed de novo generation of plasmin activity in wild-type mice and lack thereof in plasminogen knock-out recipients unless they were rescued by exogenous plasmin [52] or plasminogen (Figure 2(a)).

Our most recent observations suggest additional mechanisms underscoring the critical role for plasmin-cleaved CDCP1 during spontaneous metastasis. Specifically, we have just shown that plasmin-cleaved CDCP1 engages $\beta 1$ integrin, resulting in formation of stable complexes which trigger FAK phosphorylation and induce downstream PI3K-Akt signaling. This complexing of $\beta 1$ integrin with the cleaved CDCP1, followed by phosphorylation-dependent signal transduction, provides a novel mechanism for increased tumor cell motility which is required for cell escape from the primary tumor, invasion of local stroma, and intravasation into tumorassociated vasculature, all processes regulated in part by plasmin-executed cleavage of a transmembrane protein residing at the apex of an outside-in signaling cascade.

Figure 3 summarizes our findings and shows how different components of the uPA/plasmin system, provided either by a tumor cell or a host cell, can contribute to the generation of plasmin, cleavage of tumor cell CDCP1, and signal transduction by the cleaved CDCP1 fragment complexed with $\beta 1$ integrin. The cell surface of tumor cells expressing uPAR, uPAR-bound pro-uPA, and full-length $135-\mathrm{kDa}$ CDCP1 is depicted on the left. The plasma membrane of host cells represented by vascular cells (endothelium) and inflammatory cells (monocytes/macrophages) is depicted on the right. Although host cells can express uPAR and prouPA and various plasminogen-binding molecules, only the transmembrane plasminogen receptor $\mathrm{Plg}-\mathrm{R}_{\mathrm{KT}}$ and $\mathrm{Plg}-\mathrm{R}_{\mathrm{KT}}{ }^{-}$ bound plasminogen (Plg) and plasmin are depicted for clarity of the scheme. Briefly, we propose that tumor cell proUPA bound to UPAR is initially activated by trace plasmin, either in solution or bound to one of the plasminogen receptors. The uPAR-associated active uPA then proteolytically activates plasminogen that is bound to Plg- $\mathrm{R}_{\mathrm{KT}}$ (or other plasminogen-binding molecules). Alternatively, plasminogen can be activated by tPA. Upon activation, receptorbound plasmin, protected from natural plasmin inhibitors, can cleave transmembrane $135-\mathrm{kDa}$ CDCP1 on the surface of tumor cells and generate plasma membrane-retained $70-\mathrm{kDa}$ fragment and shed $65-\mathrm{kDa}$ fragment. Plasmin can also be released from plasminogen receptor into pericellular milieu and cleave CDCP1 as a soluble enzyme. The C-terminus of cleaved CDCP1 serves as a docking platform for Src. If the Src kinase is functionally active, it phosphorylates C-terminal tyrosine residues of cleaved CDCP1, initiating signal transduction and complex formation with $\beta 1$ integrin. This signaling cascade involves docking of $\mathrm{PKC} \delta$ to phosphorylated cleaved CDCP1 and FAK to CDCP1-bound $\beta 1$ integrin. Both $\mathrm{PKC} \delta$ and FAK become phosphorylated and functionally active, leading to activation of PI3K and PI3K-mediated activation of Akt. Ultimately, Akt-mediated phosphorylation signaling regulates tumor cell survival, via 


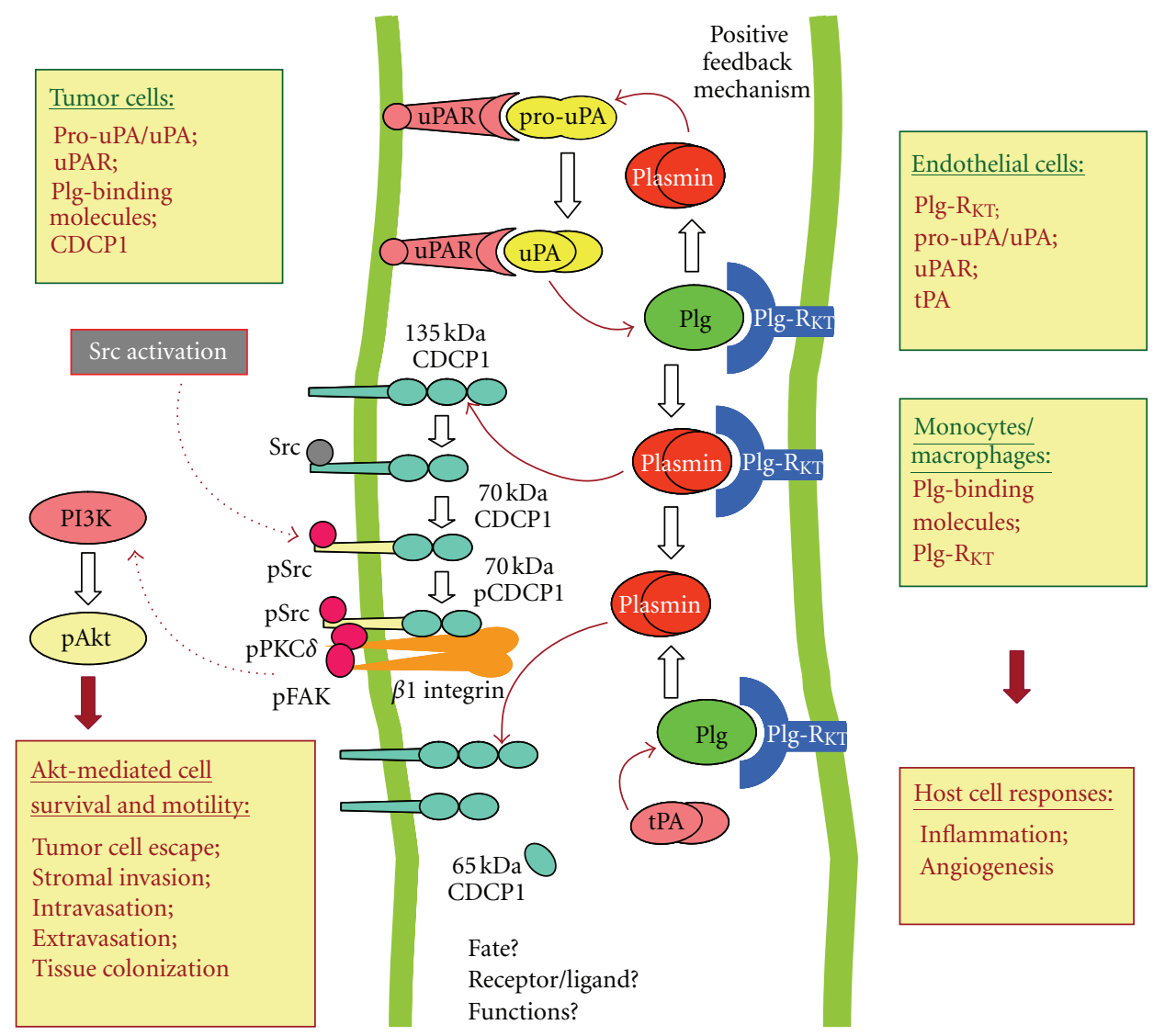

FIGURE 3: Proposed mechanism of proteolytic cleavage of CDCP1 and induction of signal transduction by de novo generated plasmin.

suppression of PARP1 cleavage and PARP1-induced apoptosis, and induces cell motility, via integrin clustering and activation of FAK. While enhanced integrin-mediated cell motility allows tumor cells to escape from the primary tumor, invade the adjacent stroma, and intravasate into the host vasculature, suppressed apoptosis allows tumor cells to survive during circulation and vascular arrest and efficiently extravasate and colonize secondary tissues to establish metastatic foci. Our findings indicate that in vivo blocking of CDCP1 cleavage upstream of CDCP1-induced prosurvival signaling provides a potential mechanism for therapeutic intervention into metastatic disease. Discovery of additional plasma membrane proteins, cleavage of which by plasmin would induce signal transduction that might regulate tumor cell fate, constitutes an exciting area of future cancer research.

6.4. Putative Transmembrane Substrates of Plasmin. In a cellfree in vitro system, plasmin and also thrombin were shown to shed the ectodomain of syndecan-4 [178]. Syndecans are single transmembrane domain proteins that through their glycosaminoglycan chains can interact with a wide array of ligands regulating many vital functions of normal and cancerous cells [179]. Syndecan ligands include growth factors such as FGF-2, VEGF, TGF- $\beta$, and also ECM molecules such as fibronectin and tenascin C. This combination of ligand diversity and the possibility that serine proteases could be involved in the shedding of syndecans ectodomains makes it tempting to speculate that plasminmediated cleavage of syndecans might modulate such cell functions as adherence to the ECM or recognition of specific matrix components. However, in contrast to clear activation-inducing effects of plasmin cleavage demonstrated for CDCP1, it is possible that plasmin-mediated shedding of syndecans in vivo would attenuate syndecan functions due to truncation of their extracellular domains and inhibition of intracellular signaling. Therefore, syndecans, including syndecans-4, may represent novel transmembrane targets, proteolytic modification of which by plasmin might induce a negative feed back mechanism.

Another putative transmembrane substrate of plasmin has been suggested by the study of the mechanisms involved in Streptococcus pneumoniae spreading [180], which demonstrated that aprotinin-sensitive plasmin activity was responsible for disruption of endothelial monolayers. Endothelial transmigration in vitro was facilitated by precoating of bacterial cells with plasminogen, allowing for efficient generation of plasmin, likely through the streptococcal streptokinase, a potent bacterial plasminogen activator. The authors showed that in vitro plasmin effectively cleaved recombinant VEcadherin, the main component of endothelial adherens complexes, and proposed that endothelial monolayers in their model system were disrupted through plasmin-mediated cleavage of intercellular junctions [180]. This finding points 
to VE-cadherin as a putative transmembrane molecule, the function of which could be regulated by de novo generated plasmin at the sites of tumor cell-host vasculature interactions.

Finally, the study of fibrinolysis-independent role of plasmin during recovery of hematopoiesis after chemical ablation with 5-fluorouracil indicated that plasmin may have yet another plasma membrane-bound target, namely, vascular adhesion molecule 1, VCAM-1 [136]. The hematopoietic recovery in wild-type mice is accompanied by transient increase of soluble VCAM in the bone marrow plasma. However, such an increase did not occur in plasminogendeficient mice, implicating plasmin in VCAM shedding. Supporting this mechanism, direct treatment of a VCAM-1positive murine stromal cell line with purified plasmin in vitro increased the levels of soluble VCAM- 1 accumulated in the conditioned medium [136]. VCAM-1 (CD106) is a type I transmembrane protein which serves as an adhesion molecule, namely, as an endothelial cell ligand for $\alpha 4 \beta 1$ or $\alpha 4 \beta 7$ integrins expressed on various blood leukocytes. VCAM-1 has been implicated in signal transduction elicited by crosstalk between endothelial cells and leukocytes, making plasmin cleavage of this molecule and its putative plasmininduced signal transduction an attractive aim for further investigations of tumor cell functions under specific physiological conditions, which facilitate de novo generation of plasmin activity, for example, during extravasation of tumor cells from the capillary bed of secondary organs.

\section{Plasmin-Mediated Cleavage of Cell Surface Molecules as a Target for Cancer Therapy}

Plasmin-mediated proteolytic modification of cell surface molecules, causing their functional activation, points to an aspect of plasmin functionality that has been overlooked or underappreciated by mainstream cancer research but likely deserves more attention and consideration. The latter becomes especially important in view of a preconceived notion that therapeutic inhibition of the proteolytic activity of plasmin, including plasmin-induced activation of certain prometastatic MMPs, could be an efficient means to control metastatic spread in cancer patients undergoing surgical removal of solid tumors. However, the broad use of antiplasmin inhibitors, resulting in the inhibition of plasminmediated fibrinolysis, can actually increase formation of microthrombi and therefore inadvertently facilitate thrombidependent survival of tumor cells [181]. In agreement with this scenario, the size of thrombi and levels of lung colonization were significantly increased in an experimental metastasis model when melanoma cells were inoculated into mice treated with aprotinin [182]. Furthermore, aprotinin treatment significantly increased spontaneous metastasis to the lung from primary tumors generated by subcutaneously implanted Lewis lung carcinoma cells [183]. The effects of genetic deficiency in plasminogen also indicate that fibrinolytic defects could constitute the main "side effects" caused by a lack of plasmin activity in mice [184]. These experimental studies and also clinical reports about termination of aprotinin trials for patients with lung, esophageal, or breast cancer (see NCT00306137 and NCT00354900 at http://clinicaltrials.gov), all, caution against indiscriminate targeting of plasmin-like serine proteases for cancer therapy.

For a long time, targeting those components of the PA system, which are responsible for activation of plasminogen or pro-uPA or inhibition of uPA activity, were considered as more promising strategies for anticancer therapy than direct inhibition of plasmin-mediated proteolysis. An emerging opinion, however, is that little progress has been made in translating the findings from test tubes, cell cultures, and even animal models into effective therapeutic approaches in patients, resulting in a paucity of clinical trials evaluating modulators of the uPA system $[7,16]$. Instead, the inhibition of proteolysis mediated by uPA-activated plasmin could be focused on preventing proteolytic modifications of specific transmembrane or cell-membrane-associated proteins, cleavage of which triggers cancer-promoting signaling in tumor and/or host cells. Such proteolysis-induced signaling can be blocked at the apex of corresponding signal transduction cascades by functionally targeting cleavable molecules, rather than by inhibiting overall activity of cleavage-executing enzymes. In this regard, we have demonstrated that ligation of CDCP1 with specific cleavage-blocking antibodies completely abrogates critical cleavage-dependent signaling, which would otherwise enhance $\beta 1$ integrinmediated motility, increase tumor cell escape, invasion, and intravasation at the primary tumor site, and help to resist apoptosis and improve survival of successfully intravasated tumor cells $[52,174]$. Furthermore, targeting the cleavage-activating step of cell surface-bound prouPA with a specific activation-preventing mAb, mAb-112, was shown by us to effectively decrease metastasis of prostate carcinoma cells in several independent models [28, 185-187].

Implemented together, specifically tailored antimetastatic tools targeting distinct transmembrane and plasma membrane-associated molecules, which are activated by limited plasmin cleavage, for example, CDCP1 [52] or pro-uPA [28, $185,187]$, can dramatically impede cancer cells from accomplishing different steps of the metastatic cascade and ultimately reduce spontaneous dissemination and tissue colonization. Finally, plasmin-cleaved portions of transmembrane molecules could also serve as biomarkers of a pathological process. Thus, just as biochemical detection of a plasmin-cleaved amino-terminal domain of the NMDA receptor can indicate an injury of the central nervous system [164], the detection of the plasmin-cleaved $65 \mathrm{kDa}$ fragment of CDCP1 may indicate ongoing dissemination of cancer cells.

\section{References}

[1] P. A. Andreasen, R. Egelund, and H. H. Petersen, "The plasminogen activation system in tumor growth, invasion, and metastasis," Cellular and Molecular Life Sciences, vol. 57, no. 1, pp. 25-40, 2000.

[2] M. S. Pepper, "Role of the matrix metalloproteinase and plasminogen activator-plasmin systems in angiogenesis," 
Arteriosclerosis, Thrombosis, and Vascular Biology, vol. 21, no. 7, pp. 1104-1117, 2001.

[3] J. M. Rakic, C. Maillard, M. Jost et al., "Role of plasminogen activator-plasmin system in tumor angiogenesis," Cellular and Molecular Life Sciences, vol. 60, no. 3, pp. 463-473, 2003.

[4] T. Syrovets and T. Simmet, "Novel aspects and new roles for the serine protease plasmin," Cellular and Molecular Life Sciences, vol. 61, no. 7-8, pp. 873-885, 2004.

[5] F. J. Castellino and V. A. Ploplis, "Structure and function of the plasminogen/plasmin system," Thrombosis and Haemostasis, vol. 93, no. 4, pp. 647-654, 2005.

[6] B. R. Binder, J. Mihaly, and G. W. Prager, "uPAR-uPA-PAI1 interactions and signaling: a vascular biologist's view," Thrombosis and Haemostasis, vol. 97, no. 3, pp. 336-342, 2007.

[7] R. Hildenbrand, H. Allgayer, A. Marx, and P. Stroebel, "Modulators of the urokinase-type plasminogen activation system for cancer," Expert Opinion on Investigational Drugs, vol. 19, no. 5, pp. 641-652, 2010.

[8] I. Zemzoum, R. E. Kates, J. S. Ross et al., "Invasion factors uPA/PAI-1 and HER2 status provide independent and complementary information on patient outcome in nodenegative breast cancer," Journal of Clinical Oncology, vol. 21, no. 6, pp. 1022-1028, 2003.

[9] P. J. Cozzi, J. Wang, W. Delprado et al., "Evaluation of urokinase plasminogen activator and its receptor in different grades of human prostate cancer," Human Pathology, vol. 37, no. 11, pp. 1442-1451, 2006.

[10] L. Zhang, Z. S. Zhao, G. Q. Ru, and J. Ma, "Correlative studies on UPA mRNA and UPAR mRNA expression with vascular endothelial growth factor, microvessel density, progression and survival time of patients with gastric cancer," World Journal of Gastroenterology, vol. 12, no. 25, pp. 3970-3976, 2006.

[11] S. F. Shariat, C. G. Roehrborn, J. D. McConnell et al., "Association of the circulating levels of the urokinase system of plasminogen activation with the presence of prostate cancer and invasion, progression, and metastasis," Journal of Clinical Oncology, vol. 25, no. 4, pp. 349-355, 2007.

[12] B. S. Nielsen, F. Rank, M. Illemann, L. R. Lund, and K. Danø, "Stromal cells associated with early invasive foci in human mammary ductal carcinoma in situ coexpress urokinase and urokinase receptor," International Journal of Cancer, vol. 120, no. 10, pp. 2086-2095, 2007.

[13] R. Hildenbrand and A. Schaaf, "The urokinase-system in tumor tissue stroma of the breast and breast cancer cell invasion," International Journal of Oncology, vol. 34, no. 1, pp. 15-23, 2009.

[14] R. Hildenbrand, M. Niedergethmann, A. Marx et al., "Amplification of the urokinase-type plasminogen activator receptor (uPAR) gene in ductal pancreatic carcinomas identifies a clinically high-risk group," American Journal of Pathology, vol. 174, no. 6, pp. 2246-2253, 2009.

[15] C. Thomssen, N. Harbeck, J. Dittmer et al., "Feasibility of measuring the prognostic factors $\mathrm{UPA}$ and PAI-1 in core needle biopsy breast cancer specimens," Journal of the National Cancer Institute, vol. 101, no. 14, pp. 1028-1029, 2009.

[16] K. Danø, N. Behrendt, G. Høyer-Hansen et al., "Plasminogen activation and cancer," Thrombosis and Haemostasis, vol. 93, no. 4, pp. 676-681, 2005.

[17] Y. Li and P. J. Cozzi, “Targeting uPA/uPAR in prostate cancer," Cancer Treatment Reviews, vol. 33, no. 6, pp. 521-527, 2007.

[18] A. H. Mekkawy, D. L. Morris, and M. H. Pourgholami, "Urokinase plasminogen activator system as a potential target for cancer therapy," Future Oncology, vol. 5, no. 9, pp. 1487-1499, 2009.

[19] D. Alfano, P. Franco, I. Vocca et al., "The urokinase plasminogen activator and its receptor. Role in cell growth and apoptosis," Thrombosis and Haemostasis, vol. 93, no. 2, pp. 205-211, 2005.

[20] M. V. Carriero, P. Franco, I. Vocca et al., "Structure, function and antagonists of urokinase-type plasminogen activator," Frontiers in Bioscience, vol. 14, no. 10, pp. 3782-3794, 2009.

[21] K. C. Robbins, L. Summaria, B. Hsieh, and R. J. Shah, "The peptide chains of human plasmin. Mechanism of activation of human plasminogen to plasmin," Journal of Biological Chemistry, vol. 242, no. 10, pp. 2333-2342, 1967.

[22] V. Schuster, B. Hügle, and K. Tefs, "Plasminogen deficiency," Journal of Thrombosis and Haemostasis, vol. 5, no. 12, pp. 2315-2322, 2007.

[23] H. Fuchs, M. M. Simon, R. Wallich, M. Bechtel, and M. D. Kramer, "Borrelia burgdorferi induces secretion of pro-urokinase-type plasminogen activator by human monocytes," Infection and Immunity, vol. 64, no. 10, pp. 4307-4312, 1996.

[24] N. Jessani, M. Humphrey, W. H. McDonald et al., "Carcinoma and stromal enzyme activity profiles associated with breast tumor growth in vivo," Proceedings of the National Academy of Sciences of the United States of America, vol. 101, no. 38, pp. 13756-13761, 2004.

[25] M. A. Madsen, E. I. Deryugina, S. Niessen, B. F. Cravatt, and J. P. Quigley, "Activity-based protein profiling implicates urokinase activation as a key step in human fibrosarcoma intravasation," Journal of Biological Chemistry, vol. 281, no. 23, pp. 15997-16005, 2006.

[26] D. R. Croucher, D. N. Saunders, S. Lobov, and M. Ranson, "Revisiting the biological roles of PAI2 (SERPINB2) in cancer," Nature Reviews Cancer, vol. 8, no. 7, pp. 535-545, 2008.

[27] R. Lacroix, F. Sabatier, A. Mialhe et al., "Activation of plasminogen into plasmin at the surface of endothelial microparticles: a mechanism that modulates angiogenic properties of endothelial progenitor cells in vitro," Blood, vol. 110, no. 7, pp. 2432-2439, 2007.

[28] E. M. Bekes, E. I. Deryugina, T. A. Kupriyanova, E. Zajac, K. A. Botkjaer, and P. A. Andreasen, "Quigley JP Activation of pro-uPA is critical for initial escape from the primary tumor and hematogenous dissemination of human carcinoma cells," Neoplasia, vol. 13, pp. 806-821, 2011.

[29] M. Kwon, T. J. MacLeod, Y. Zhang, and D. M. Waisman, "S100A10, annexin A2, and annexin A2 heterotetramer as candidate plasminogen receptors," Frontiers in Bioscience, vol. 10, no. 1, pp. 300-325, 2005.

[30] E. F. Plow, D. E. Freaney, J. Plescia, and L. A. Miles, "The plasminogen system and cell surfaces: evidence for plasminogen and urokinase receptors on the same cell type," Journal of Cell Biology, vol. 103, no. 6 I, pp. 2411-2420, 1986.

[31] T. Herren, C. Swaisgood, and E. F. Plow, "Regulation of plasminogen receptors," Frontiers in Bioscience, vol. 8, pp. d1-d8, 2003.

[32] J. P. Quigley, "Deryugina EI Combating angiogenesis early: potential of targeting tumor-recruited neutrophils in cancer therapy," Future Oncology, vol. 8, pp. 5-8, 2012.

[33] L. A. Miles, C. M. Dahlberg, J. Plescia, J. Felez, K. Kato, and E. F. Plow, "Role of cell-surface lysines in plasminogen binding to cells: identification of $\alpha$-enolase as a candidate plasminogen receptor," Biochemistry, vol. 30, no. 6, pp. 1682$1691,1991$.

[34] M. Wygrecka, L. M. Marsh, R. E. Morty et al., "Enolase-1 promotes plasminogen-mediated recruitment of monocytes 
to the acutely inflamed lung," Blood, vol. 113, no. 22, pp. 5588-5598, 2009.

[35] T. Herren, T. A. Burke, R. Das, and E. F. Plow, "Identification of histone $\mathrm{H} 2 \mathrm{~B}$ as a regulated plasminogen receptor," Biochemistry, vol. 45, no. 31, pp. 9463-9474, 2006.

[36] R. Das, T. Burke, and E. F. Plow, "Histone H2B as a functionally important plasminogen receptor on macrophages," Blood, vol. 110, no. 10, pp. 3763-3772, 2007.

[37] L. A. Miles, N. M. Andronicos, N. Baik, and R. J. Parmer, "Cell-surface actin binds plasminogen and modulates neurotransmitter release from catecholaminergic cells," Journal of Neuroscience, vol. 26, no. 50, pp. 13017-13024, 2006.

[38] N. A. Lokman, M. P. Ween, M. K. Oehler, and C. Ricciardelli, "The role of annexin A2 in tumorigenesis and cancer progression," Cancer Microenvironment, vol. 2, pp. 199-208, 2011.

[39] K. A. Hajjar, A. T. Jacovina, and J. Chacko, "An endothelial cell receptor for plasminogen/tissue plasminogen activator. I. Identity with annexin II," Journal of Biological Chemistry, vol. 269, no. 33, pp. 21191-21197, 1994.

[40] G. M. Cesarman, C. A. Guevara, and K. A. Hajjar, "An endothelial cell receptor for plasminogen/tissue plasminogen activator (t-PA). II. Annexin II-mediated enhancement of tPA-dependent plasminogen activation," Journal of Biological Chemistry, vol. 269, no. 33, pp. 21198-21203, 1994.

[41] A. Semov, M. J. Moreno, A. Onichtchenko et al., "Metastasisassociated protein S100A4 induces angiogenesis through interaction with annexin II and accelerated plasmin formation," Journal of Biological Chemistry, vol. 280, no. 21, pp. 20833-20841, 2005.

[42] Y. Laumonnier, T. Syrovets, L. Burysek, and T. Simmet, "Identification of the annexin A2 heterotetramer as a receptor for the plasmin-induced signaling in human peripheral monocytes," Blood, vol. 107, no. 8, pp. 3342-3349, 2006.

[43] L. Zhang, D. K. Fogg, and D. M. Waisman, "RNA interference-mediated silencing of the S100A10 gene attenuates plasmin generation and invasiveness of colo 222 colorectal cancer cells," Journal of Biological Chemistry, vol. 279, no. 3, pp. 2053-2062, 2004.

[44] C. Brownstein, A. B. Deora, A. T. Jacovina et al., "Annexin II mediates plasminogen-dependent matrix invasion by human monocytes: enhanced expression by macrophages," Blood, vol. 103, no. 1, pp. 317-324, 2004.

[45] Y. Zhang, Z. H. Zhou, T. H. Bugge, and L. M. Wahl, "Urokinase-type plasminogen activator stimulation of monocyte matrix metalloproteinase- 1 production is mediated by plasmin-dependent signaling through annexin A2 and inhibited by inactive plasmin," Journal of Immunology, vol. 179, no. 5, pp. 3297-3304, 2007.

[46] K. L. He, G. Sui, H. Xiong et al., "Feedback regulation of endothelial cell surface plasmin generation by PKCdependent phosphorylation of annexin A2," Journal of Biological Chemistry, vol. 286, no. 17, pp. 15428-15439, 2011.

[47] K. D. Phipps, A. P. Surette, and P. A. O'Connell, "Waisman DM Plasminogen receptor S100A10 is essential for the migration of tumor-promoting macrophages into tumor sites," Cancer Research, vol. 71, pp. 6676-6683, 2011.

[48] E. F. Plow and R. Das, "Enolase-1 as a plasminogen receptor," Blood, vol. 113, no. 22, pp. 5371-5372, 2009.

[49] N. M. Andronicos, E. I. Chen, N. Baik et al., "Proteomicsbased discovery of a novel, structurally unique, and developmentally regulated plasminogen receptor, Plg- $\mathrm{R}_{\mathrm{KT}}$, a major regulator of cell surface plasminogen activation," Blood, vol. 115, no. 7, pp. 1319-1330, 2010.
[50] S. Lighvani, N. Baik, J. E. Diggs, S. Khaldoyanidi, and R. J. Parmer, "Miles LA Regulation of macrophage migration by a novel plasminogen receptor Plg-R KT," Blood, vol. 118, pp. 5622-5630, 2011.

[51] H. Bai, N. Baik, W. B. Kiosses, S. Krajewski, and L. A. Miles, "Parmer RJ The novel plasminogen receptor, plasminogen receptor(KT) (Plg-R(KT)), regulates catecholamine release," The Journal of Biological Chemistry, vol. 286, pp. 3312533133, 2011.

[52] B. Casar, Y. He, M. Iconomou, J. D. Hooper, J. P. Quigley, and E. I. Deryugina, "Blocking of CDCP1 cleavage in vivo prevents Akt-dependent survival and inhibits metastatic colonization through PARP1-mediated apoptosis of cancer cells," Oncogene, December 2011.

[53] L. Ossowski, "In vivo invasion of modified chorioallantoic membrane by tumor cells: the role of cell surface-bound urokinase," Journal of Cell Biology, vol. 107, no. 6 I, pp. 24372445, 1988.

[54] S. M. K. Pulukuri and J. S. Rao, "Small interfering RNA-directed reversal of urokinase plasminogen activator demethylation inhibits prostate tumor growth and metastasis," Cancer Research, vol. 67, no. 14, pp. 6637-6646, 2007.

[55] L. S. Gutierrez, A. Schulman, T. Brito-Robinson, F. Noria, V. A. Ploplis, and F. J. Castellino, "Tumor development is retarded in mice lacking the gene for urokinase-type plasminogen activator or its inhibitor, plasminogen activator inhibitor-1," Cancer Research, vol. 60, no. 20, pp. 5839-5847, 2000.

[56] J. Zhang, S. Sud, K. Mizutani, M. R. Gyetko, and K. J. Pienta, "Activation of urokinase plasminogen activator and its receptor axis is essential for macrophage infiltration in a prostate cancer mouse model," Neoplasia, vol. 13, no. 1, pp. 23-30, 2011.

[57] A. Curino, D. J. Mitola, H. Aaronson et al., "Plasminogen promotes sarcoma growth and suppresses the accumulation of tumor-infiltrating macrophages," Oncogene, vol. 21, no. 57, pp. 8830-8842, 2002.

[58] T. H. Bugge, L. R. Lund, K. K. Kombrinck et al., "Reduced metastasis of Polyoma virus middle $\mathrm{T}$ antigen-induced mammary cancer in plasminogen-deficient mice," Oncogene, vol. 16, no. 24, pp. 3097-3104, 1998.

[59] K. Almholt, L. R. Lund, J. Rygaard et al., "Reduced metastasis of transgenic mammary cancer in urokinase-deficient mice," International Journal of Cancer, vol. 113, no. 4, pp. 525-532, 2005.

[60] J. S. Palumbo, K. E. Talmage, H. Liu, C. M. La Jeunesse, D. P. Witte, and J. L. Degen, "Plasminogen supports tumor growth through a fibrinogen-dependent mechanism linked to vascular patency," Blood, vol. 102, no. 8, pp. 2819-2827, 2003.

[61] T. H. Bugge, K. W. Kombrinck, Q. Xiao et al., "Growth and dissemination of Lewis lung carcinoma in plasminogendeficient mice," Blood, vol. 90, no. 11, pp. 4522-4531, 1997.

[62] C. W. Oh, J. Hoover-Plow, and E. F. Plow, "The role of plasminogen in angiogenesis in vivo," Journal of Thrombosis and Haemostasis, vol. 1, no. 8, pp. 1683-1687, 2003.

[63] G. Perides, Y. Zhuge, T. Lin, M. F. Stins, R. T. Bronson, and J. K. Wu, "The fibrinolytic system facilitates tumor cell migration across the blood-brain barrier in experimental melanoma brain metastasis," BMC Cancer, vol. 6, article 56, 2006.

[64] V. A. Ploplis, E. L. French, P. Carmeliet, D. Collen, and E. F. Plow, "Plasminogen deficiency differentially affects recruitment of inflammatory cell populations in mice," Blood, vol. 91, no. 6, pp. 2005-2009, 1998. 
[65] Y. Gong, E. Hart, A. Shchurin, and J. Hoover-Plow, "Inflammatory macrophage migration requires MMP-9 activation by plasminogen in mice," Journal of Clinical Investigation, vol. 118, no. 9, pp. 3012-3024, 2008.

[66] J. Massagué, S. W. Blain, and R. S. Lo, "TGF $\beta$ signaling in growth control, cancer, and heritable disorders," Cell, vol. 103, no. 2, pp. 295-309, 2000.

[67] R. M. Lyons, J. Keski-Oja, and H. L. Moses, "Proteolytic activation of latent transforming growth factor- $\beta$ from fibroblast-conditioned medium," Journal of Cell Biology, vol. 106, no. 5, pp. 1659-1665, 1988.

[68] G. Jenkins, "The role of proteases in transforming growth factor- $\beta$ activation," International Journal of Biochemistry and Cell Biology, vol. 40, no. 6-7, pp. 1068-1078, 2008.

[69] R. M. Lyons, L. E. Gentry, A. F. Purchio, and H. L. Moses, "Mechanism of activation of latent recombinant transforming growth factor $\beta 1$ by plasmin," Journal of Cell Biology, vol. 110, no. 4, pp. 1361-1367, 1990.

[70] J. Taipale, K. Koli, and J. Keski-Oja, "Release of transforming growth factor- $\beta 1$ from the pericellular matrix of cultured fibroblasts and fibrosarcoma cells by plasmin and thrombin," Journal of Biological Chemistry, vol. 267, no. 35, pp. 25378 25384, 1992.

[71] D. J. Falcone, T. A. McCaffrey, A. Haimovitz-Friedman, J. A. Vergilio, and A. C. Nicholson, "Macrophage and foam cell release of matrix-bound growth factors. Role of plasminogen activation," Journal of Biological Chemistry, vol. 268, no. 16, pp. 11951-11958, 1993.

[72] D. J. Grainger, L. Wakefield, H. W. Bethell, R. W. Farndale, and J. C. Metcalfe, "Release and activation of platelet latent TGF- $\beta$ in blood clots during dissolution with plasmin," Nature Medicine, vol. 1, no. 9, pp. 932-937, 1995.

[73] N. Khalil, S. Corne, C. Whitman, and H. Yacyshyn, "Plasmin regulates the activation of cell-associated latent TGF- $\beta 1$ secreted by rat alveolar macrophages after in vivo bleomycin injury," American Journal of Respiratory Cell and Molecular Biology, vol. 15, no. 2, pp. 252-259, 1996.

[74] D. Padua and J. Massagué, "Roles of TGF $\beta$ in metastasis," Cell Research, vol. 19, no. 1, pp. 89-102, 2009.

[75] T. H. Bugge, M. J. Flick, C. C. Daugherty, and J. L. Degen, "Plasminogen deficiency causes severe thrombosis but is compatible with development and reproduction," Genes and Development, vol. 9, no. 7, pp. 794-807, 1995.

[76] V. A. Ploplis, P. Carmeliet, S. Vazirzadeh et al., "Effects of disruption of the plasminogen gene on thrombosis, growth, and health in mice," Circulation, vol. 92, no. 9, pp. 25852593, 1995.

[77] J. Rømer, T. H. Bugge, C. Pyke et al., "Impaired wound healing in mice with a disrupted plasminogen gene," Nature Medicine, vol. 2, no. 3, pp. 287-292, 1996.

[78] P. Carmeliet, L. Schoonjans, L. Kieckens et al., "Physiological consequences of loss of plasminogen activator gene function in mice," Nature, vol. 368, no. 6470, pp. 419-424, 1994.

[79] C. G. Lee, R. J. Homer, Z. Zhu et al., "Interleukin-13 induces tissue fibrosis by selectively stimulating and activating transforming growth factor $\beta 1$," Journal of Experimental Medicine, vol. 194, no. 6, pp. 809-821, 2001.

[80] O. Saksela and D. B. Rifkin, "Release of basic fibroblast growth factor-heparan sulfate complexes from endothelial cells by plasminogen activator-mediated proteolytic activity," Journal of Cell Biology, vol. 110, no. 3, pp. 767-775, 1990.

[81] M. Presta, P. Dell'Era, S. Mitola, E. Moroni, R. Ronca, and M. Rusnati, "Fibroblast growth factor/fibroblast growth factor receptor system in angiogenesis," Cytokine and Growth Factor Reviews, vol. 16, no. 2, pp. 159-178, 2005.
[82] N. Turner and R. Grose, "Fibroblast growth factor signalling: from development to cancer," Nature Reviews Cancer, vol. 10, no. 2, pp. 116-129, 2010.

[83] J. M. Whitelock, A. D. Murdoch, R. V. Iozzo, and P. A. Underwood, "The degradation of human endothelial cellderived perlecan and release of bound basic fibroblast growth factor by stromelysin, collagenase, plasmin, and heparanases," Journal of Biological Chemistry, vol. 271, no. 17, pp. 10079-10086, 1996.

[84] S. J. George, J. L. Johnson, M. A. Smith, and C. L. Jackson, "Plasmin-mediated fibroblast growth factor-2 mobilisation supports smooth muscle cell proliferation in human saphenous vein," Journal of Vascular Research, vol. 38, no. 5, pp. 492-501, 2001.

[85] A. Gualandris and M. Presta, "Transcriptional and posttranscriptional regulation of urokinase-type plasminogen activator expression in endothelial cells by basic fibroblast growth factor," Journal of Cellular Physiology, vol. 162, no. 3, pp. 400-409, 1995.

[86] D. Ribatti, D. Leali, A. Vacca et al., "In vivo angiogenic activity of urokinase: role of endogenous fibroblast growth factor-2," Journal of Cell Science, vol. 112, no. 23, pp. 42134221, 1999.

[87] V. C. Ardi, P. E. Van den Steen, G. Opdenakker, B. Schweighofer, E. I. Deryugina, and J. P. Quigley, "Neutrophil MMP-9 proenzyme, unencumbered by TIMP-1, undergoes efficient activation in vivo and catalytically induces angiogenesis via a basic fibroblast growth factor (FGF-2)/FGFR-2 pathway," Journal of Biological Chemistry, vol. 284, no. 38, pp. 25854-25866, 2009.

[88] C. S. Gondi, S. S. Lakka, D. H. Dinh, W. C. Olivero, and M. Gujrati, "Rao JS Downregulation of uPA, uPAR and MMP9 using small, interfering, hairpin RNA, (siRNA) inhibits glioma cell invasion, angiogenesis and tumor growth," Neuron Glia Biology, vol. 1, pp. 165-176, 2004.

[89] W. G. Jiang, T. A. Martin, C. Parr, G. Davies, K. Matsumoto, and T. Nakamura, "Hepatocyte growth factor, its receptor, and their potential value in cancer therapies," Critical Reviews in Oncology/Hematology, vol. 53, no. 1, pp. 35-69, 2005.

[90] N. Hattori, S. Mizuno, Y. Yoshida et al., "The Plasminogen Activation System Reduces Fibrosis in the Lung by a Hepatocyte Growth Factor-Dependent Mechanism," American Journal of Pathology, vol. 164, no. 3, pp. 1091-1098, 2004.

[91] H. Matsuoka, T. H. Sisson, T. Nishiuma, and R. H. Simon, "Plasminogen-mediated activation and release of hepatocyte growth factor from extracellular matrix," American Journal of Respiratory Cell and Molecular Biology, vol. 35, no. 6, pp. 705-713, 2006.

[92] Q. Jiang, L. Taupenot, S. K. Mahata et al., "Proteolytic cleavage of chromogranin A (CgA) by plasmin: selective liberation of a specific bioactive CgA fragment that regulates catecholamine release," Journal of Biological Chemistry, vol. 276, no. 27, pp. 25022-25029, 2001.

[93] N. Wang, L. Zhang, L. Miles, and J. Hoover-Plow, "Plasminogen regulates pro-opiomelanocortin processing," Journal of Thrombosis and Haemostasis, vol. 2, no. 5, pp. 785-796, 2004.

[94] K. Gray and V. Ellis, "Activation of pro-BDNF by the pericellular serine protease plasmin," FEBS Letters, vol. 582, no. 6, pp. 907-910, 2008.

[95] U. R. Pendurthi, M. Ngyuen, P. Andrade-Gordon, L. C. Petersen, and L. V. M. Rao, "Plasmin induces Cyr61 gene expression in fibroblasts via protease-activated receptor-1 and p44/42 mitogen-activated protein kinase-dependent 
signaling pathway," Arteriosclerosis, Thrombosis, and Vascular Biology, vol. 22, no. 9, pp. 1421-1426, 2002.

[96] C. C. Chen, F. E. Mo, and L. F. Lau, "The angiogenic factor Cyr61 activates a genetic program for wound healing in human skin fibroblasts," Journal of Biological Chemistry, vol. 276, no. 50, pp. 47329-47337, 2001.

[97] S. K. Mandal, L. V. M. Rao, T. T. T. Tran, and U. R. Pendurthi, "A novel mechanism of plasmin-induced mitogenesis in fibroblasts," Journal of Thrombosis and Haemostasis, vol. 3, no. 1, pp. 163-169, 2005.

[98] M. Kapoor, Q. Zhou, F. Otero et al., "Evidence for annexin IIS100A10 complex and plasmin in mobilization of cytokine activity of human TrpRS," Journal of Biological Chemistry, vol. 283, no. 4, pp. 2070-2077, 2008.

[99] G. Murphy, S. Atkinson, R. Ward, J. Gavrilovic, and J. J. Reynolds, "The role of plasminogen activators in the regulation of connective tissue metalloproteinases," Annals of the New York Academy of Sciences, vol. 667, pp. 1-12, 1992.

[100] Z. Werb, "ECM and cell surface proteolysis: regulating cellular ecology," Cell, vol. 91, no. 4, pp. 439-442, 1997.

[101] G. A. Grant, A. Z. Eisen, and B. L. Marmer, "The activation of human skin fibroblast procollagenase. Sequence identification of the major conversion products," Journal of Biological Chemistry, vol. 262, no. 12, pp. 5886-5889, 1987.

[102] Y. A. DeClerck, T. D. Yean, H. S. Lu, J. Ting, and K. E. Langley, "Inhibition of autoproteolytic activation of interstitial procollagenase by recombinant metalloproteinase inhibitor MI/TIMP-2," Journal of Biological Chemistry, vol. 266, no. 6, pp. 3893-3899, 1991.

[103] A. Santala, J. Saarinen, P. Kovanen, and P. Kuusela, "Activation of interstitial collagenase, MMP-1, by Staphylococcus aureus cells having surface-bound plasmin: a novel role of plasminogen receptors of bacteria," FEBS Letters, vol. 461, no. 3, pp. 153-156, 1999.

[104] R. Mazzieri, L. Masiero, L. Zanetta et al., "Control of type IV collagenase activity by the urokinase-plasmin system: a regulatory mechanism with cell-bound reactants," $E M B O$ Journal, vol. 16, no. 9, pp. 2319-2332, 1997.

[105] S. Monea, K. Lehti, J. Keski-Oja, and P. Mignatti, "Plasmin activates pro-matrix metalloproteinase- 2 with a membranetype 1 matrix metalloproteinase-dependent mechanism," Journal of Cellular Physiology, vol. 192, no. 2, pp. 160-170, 2002.

[106] N. Ramos-DeSimone, E. Hahn-Dantona, J. Sipley, H. Nagase, D. L. French, and J. P. Quigley, "Activation of matrix metalloproteinase-9 (MMP-9) via a converging plasmin/stromelysin-1 cascade enhances tumor cell invasion," Journal of Biological Chemistry, vol. 274, no. 19, pp. 13066-13076, 1999.

[107] Z. Liu, N. Li, L. A. Diaz, J. M. Shipley, R. M. Senior, and Z. Werb, "Synergy between a plasminogen cascade and MMP-9 in autoimmune disease," Journal of Clinical Investigation, vol. 115, no. 4, pp. 879-887, 2005.

[108] V. Knäuper, H. Will, C. López-Otin et al., "Cellular mechanisms for human procollagenase-3 (MMP-13) activation. Evidence that MT1-MMP (MMP-14) and gelatinase A (MMP-2) are able to generate active enzyme," Journal of Biological Chemistry, vol. 271, no. 29, pp. 17124-17131, 1996.

[109] G. Murphy, H. Stanton, S. Cowell et al., "Mechanisms for pro matrix metalloproteinase activation," APMIS, vol. 107, no. 1, pp. 38-44, 1999.

[110] P. Carmeliet, L. Moons, R. Lijnen et al., "Urokinase-generated plasmin activates matrix metalloproteinases during aneurysm formation," Nature Genetics, vol. 17, no. 4, pp. 439-444, 1997.
[111] C. S. He, S. M. Wilhelm, A. P. Pentland et al., "Tissue cooperation in a proteolytic cascade activating human interstitial collagenase," Proceedings of the National Academy of Sciences of the United States of America, vol. 86, no. 8, pp. 2632-2636, 1989.

[112] T. Ishida, H. Tsukada, T. Hasegawa, H. Yoshizawa, and F. Gejyo, "Matrix metalloproteinase-1 activation via plasmin generated on alveolar epithelial cell surfaces," Lung, vol. 184, no. 1, pp. 15-19, 2006.

[113] G. D. Pins, M. E. Collins-Pavao, L. Van De Water, M. L. Yarmush, and J. R. Morgan, "Plasmin triggers rapid contraction and degradation of fibroblast- populated collagen lattices," Journal of Investigative Dermatology, vol. 114, no. 4, pp. 647-653, 2000.

[114] S. Brodsky, J. Chen, A. Lee, K. Akassoglou, J. Norman, and M. S. Goligorsky, "Plasmin-dependent and -independent effects of plasminogen activators and inhibitor-1 on ex vivo angiogenesis," American Journal of Physiology, vol. 281, no. 4, pp. H1784-H1792, 2001.

[115] C. Legrand, M. Polette, J. M. Tournier et al., "uPA/plasmin system-mediated MMP-9 activation is implicated in bronchial epithelial cell migration," Experimental Cell Research, vol. 264, no. 2, pp. 326-336, 2001.

[116] A. Zijlstrat, R. T. Aimes, D. Zhu et al., "Collagenolysisdependent angiogenesis mediated by matrix metalloproteinase-13 (collagenase-3)," Journal of Biological Chemistry, vol. 279, no. 26, pp. 27633-27645, 2004.

[117] L. R. Lund, K. A. Green, A. A. Stoop et al., "Plasminogen activation independent of uPA and tPA maintains wound healing in gene-deficient mice," The EMBO Journal, vol. 25, no. 12 , pp. 2686-2697, 2006.

[118] A. Juncker-Jensen and L. R. Lund, "Phenotypic overlap between MMP-13 and the plasminogen activation system during wound healing in mice," PLoS ONE, vol. 6, no. 2, Article ID e16954, 2011.

[119] S. Frøssing, B. Rønø, A. Hald, J. Rømer, and L. R. Lund, "Skin wound healing in MMP2-deficient and MMP2/Plasminogen double-deficient mice," Experimental Dermatology, vol. 19, no. 8, pp. e234-e240, 2010.

[120] B. Heissig, L. R. Lund, H. Akiyama et al., "The plasminogen fibrinolytic pathway is required for hematopoietic regeneration," Cell Stem Cell, vol. 1, no. 6, pp. 658-670, 2007.

[121] B. Heissig, K. Hattori, S. Dias et al., "Recruitment of stem and progenitor cells from the bone marrow niche requires MMP-9 mediated release of Kit-ligand," Cell, vol. 109, no. 5, pp. 625-637, 2002.

[122] B. Heissig, M. Ohki, M. Ishihara et al., "Contribution of the fibrinolytic pathway to hematopoietic regeneration," Journal of Cellular Physiology, vol. 221, no. 3, pp. 521-525, 2009.

[123] B. Heissig, M. Ohki-Koizumi, Y. Tashiro, I. Gritli, K. SatoKusubata, and K. Hattori, "New functions of the fibrinolytic system in bone marrow cell-derived angiogenesis," International Journal of Hematology, vol. 95, pp. 131-137, 2012.

[124] M. Ishihara, C. Nishida, Y. Tashiro et al., "Plasmin inhibitor reduces T-cell lymphoid tumor growth by suppressing matrix metalloproteinase-9-dependent $\mathrm{CD} 11 \mathrm{~b}^{+} / \mathrm{F} 4 / 80^{+}$myeloid cell recruitment," Leukemia, vol. 26, no. 2, pp. 332-339, 2012.

[125] L. A. Liotta, R. H. Goldfarb, R. Brundage et al., "Effect of plasminogen activator (urokinase), plasmin, and thrombin on glycoprotein and collagenous components of basement membrane," Cancer Research, vol. 41, no. 11 I, pp. 4629-4636, 1981.

[126] L. E. Goldfinger, M. S. Stack, and J. C. R. Jones, "Processing of laminin-5 and its functional consequences: role of 
plasmin and tissue-type plasminogen activator," Journal of Cell Biology, vol. 141, no. 1, pp. 255-265, 1998.

[127] L. E. Goldfinger, L. Jiang, S. B. Hopkinson, M. S. Stack, and J. C. R. Jones, "Spatial regulation and activity modulation of plasmin by high affinity binding to the $\mathrm{G}$ domain of the $\alpha 3$ subunit of laminin-5," Journal of Biological Chemistry, vol. 275, no. 45, pp. 34887-34893, 2000.

[128] A. Gutiérrez-Fernández, N. A. Gingles, H. Bai, F. J. Castellino, R. J. Parmer, and L. A. Miles, "Plasminogen enhances neuritogenesis on laminin-1," Journal of Neuroscience, vol. 29, no. 40, pp. 12393-12400, 2009.

[129] A. E. Skrzypiec, R. Maiya, Z. Chen, R. Pawlak, and S. Strickland, "Plasmin-mediated degradation of laminin $\gamma-1$ is critical for ethanol-induced neurodegeneration," Biological Psychiatry, vol. 66, no. 8, pp. 785-794, 2009.

[130] S. E. Tsirka, T. H. Bugge, J. L. Degen, and S. Strickland, "Neuronal death in the central nervous system demonstrates a non-fibrin substrate for plasmin," Proceedings of the National Academy of Sciences of the United States of America, vol. 94, no. 18, pp. 9779-9781, 1997.

[131] Z. L. Chen and S. Strickland, "Neuronal death in the hippocampus is promoted by plasmin-catalyzed degradation of laminin," Cell, vol. 91, no. 7, pp. 917-925, 1997.

[132] Z. L. Chen, H. Yu, W. M. Yu, R. Pawlak, and S. Strickland, "Proteolytic fragments of laminin promote excitotoxic neurodegeneration by up-regulation of the KA1 subunit of the kainate receptor," Journal of Cell Biology, vol. 183, no. 7, pp. 1299-1313, 2008.

[133] R. Pankov and K. M. Yamada, "Fibronectin at a glance," Journal of Cell Science, vol. 115, no. 20, pp. 3861-3863, 2002.

[134] J. C. Horowitz, D. S. Rogers, R. H. Simon, T. H. Sisson, and V. J. Thannickal, "Plasminogen activation-induced pericellular fibronectin proteolysis promotes fibroblast apoptosis," American Journal of Respiratory Cell and Molecular Biology, vol. 38, no. 1, pp. 78-87, 2008.

[135] S. Selvarajan, L. R. Lund, T. Takeuchi, C. S. Craik, and Z. Werb, "A plasma kallikrein-dependent plasminogen cascade required for adipocyte differentiation," Nature Cell Biology, vol. 3, no. 3, pp. 267-275, 2001.

[136] M. Tjwa, R. Moura, L. Moons et al., "Fibrinolysis-independent role of plasmin and its activators in the haematopoietic recovery after myeloablation," Journal of Cellular and Molecular Medicine, vol. 13, no. 11-12, pp. 4587-4595, 2009.

[137] G. Malik, L. M. Knowles, R. Dhir et al., "Plasma fibronectin promotes lung metastasis by contributions to fibrin clots and tumor cell invasion," Cancer Research, vol. 70, no. 11, pp. 4327-4334, 2010.

[138] Z. Gechtman, R. Sharma, T. Kreizman, M. Fridkin, and S. Shaltiel, "Synthetic peptides derived from the sequence around the plasmin cleavage site in vitronectin. Use in mappng the PAI-1 binding site," FEBS Letters, vol. 315, no. 3, pp. 293-297, 1993.

[139] D. A. Waltz, L. R. Natkin, R. M. Fujita, Y. Wei, and H. A. Chapman, "Plasmin and plasminogen activator inhibitor type 1 promote cellular motility by regulating the interaction between the urokinase receptor and vitronectin," Journal of Clinical Investigation, vol. 100, no. 1, pp. 58-67, 1997.

[140] D. Gundersen, C. Trân-Thang, B. Sordat, F. Mourali, and C. Rüegg, "Plasmin-induced proteolysis of tenascin-C: modulation by $\mathrm{T}$ lymphocyte-derived urokinase-type plasminogen activator and effect on T lymphocyte adhesion, activation, and cell clustering," Journal of Immunology, vol. 158, no. 3, pp. 1051-1060, 1997.
[141] J. T. O’Connell, H. Sugimoto, V. G. Cooke et al., "VEGF$\mathrm{A}$ and Tenascin-C produced by $\mathrm{S} 100 \mathrm{~A} 4^{+}$stromal cells are important for metastatic colonization," Proceedings of the National Academy of Sciences of the United State of America, vol. 108, pp. 16002-16007, 2011.

[142] T. Oskarsson, S. Acharyya, X. H. F. Zhang et al., "Breast cancer cells produce tenascin $\mathrm{C}$ as a metastatic niche component to colonize the lungs," Nature Medicine, vol. 17, no. 7, pp. 867-874, 2011.

[143] B. Christensen, L. Schack, E. Kläning, and E. S. Sørensen, "Osteopontin is cleaved at multiple sites close to its integrinbinding motifs in milk and is a novel substrate for plasmin and cathepsin D," Journal of Biological Chemistry, vol. 285, no. 11, pp. 7929-7937, 2010.

[144] S. T. Barry, S. B. Ludbrook, E. Murrison, and C. M. T. Horgan, "A regulated interaction between $\alpha 5 \beta 1$ integrin and osteopontin," Biochemical and Biophysical Research Communications, vol. 267, no. 3, pp. 764-769, 2000.

[145] R. Agnihotri, H. C. Crawford, H. Haro, L. M. Matrisian, M. C. Havrda, and L. Liaw, "Osteopontin, a novel substrate for matrix metalloproteinase-3 (stromelysin-1) and matrix metalloproteinase-7 (Matrilysin)," Journal of Biological Chemistry, vol. 276, no. 30, pp. 28261-28267, 2001.

[146] S. K. Nilsson, H. M. Johnston, G. A. Whitty et al., "Osteopontin, a key component of the hematopoietic stem cell niche and regulator of primitive hematopoietic progenitor cells," Blood, vol. 106, no. 4, pp. 1232-1239, 2005.

[147] T. Iwaki, C. Malinverno, D. Smith et al., "The generation and characterization of mice expressing a plasmin-inactivating active site mutation," Journal of Thrombosis and Haemostasis, vol. 8, no. 10, pp. 2341-2344, 2010.

[148] S. R. Coughlin, "Thrombin signalling and protease-activated receptors," Nature, vol. 407, no. 6801, pp. 258-264, 2000.

[149] V. S. Ossovskaya and N. W. Bunnett, "Protease-activated receptors: contribution to physiology and disease," Physiological Reviews, vol. 84, no. 2, pp. 579-621, 2004.

[150] T. K. H. Vu, D. T. Hung, V. I. Wheaton, and S. R. Coughlin, "Molecular cloning of a functional thrombin receptor reveals a novel proteolytic mechanism of receptor activation," Cell, vol. 64, no. 6, pp. 1057-1068, 1991.

[151] V. Vouret-Craviari, D. Grall, J. C. Chambard, U. B. Rasmussen, J. Pouyssegur, and E. Van Obberghen-Schilling, "Post-translational and activation-dependent modifications of the G protein-coupled thrombin receptor," Journal of Biological Chemistry, vol. 270, no. 14, pp. 8367-8372, 1995.

[152] M. J. Ludeman, H. Kataoka, Y. Srinivasan, N. L. Esmon, C. T. Esmon, and S. R. Coughlin, "PAR1 cleavage and signaling in response to activated protein C and thrombin," Journal of Biological Chemistry, vol. 280, no. 13, pp. 13122-13128, 2005.

[153] R. D. Loberg, K. Tantivejkul, M. Craig, C. K. Neeley, and K. J. Pienta, "PAR1-mediated RhoA activation facilitates CCL2-induced chemotaxis in PC-3 cells," Journal of Cellular Biochemistry, vol. 101, no. 5, pp. 1292-1300, 2007.

[154] D. Fujimoto, Y. Hirono, T. Goi, K. Katayama, S. Matsukawa, and A. Yamaguchi, "The activation of proteinase-activated receptor-1 (PAR1) mediates gastric cancer cell proliferation and invasion," BMC Cancer, vol. 10, article 443, 2010.

[155] M. T. Garcia-Lopez, M. Gutierrez-Rodriguez, and R. Herranz, "Thrombin-activated receptors: promising targets for cancer therapy?" Current Medicinal Chemistry, vol. 17, pp. 109-128, 2010.

[156] R. Ramachandran, F. Noorbakhsh, K. Defea, and M. D. Hollenberg, "Targeting proteinase-activated receptors: 
therapeutic potential and challenges," Nature Reviews Drug Discovery, vol. 11, no. 1, pp. 69-86, 2012.

[157] A. Kuliopulos, L. Covic, S. K. Seeley, P. J. Sheridan, J. Helin, and C. E. Costello, "Plasmin desensitization of the PAR1 thrombin receptor: kinetics, sites of truncation, and implications for thrombolytic therapy," Biochemistry, vol. 38, no. 14, pp. 4572-4585, 1999.

[158] D. Loew, C. Perrault, M. Morales et al., "Proteolysis of the exodomain of recombinant protease-activated receptors: prediction of receptor activation or inactivation by MALDI mass spectrometry," Biochemistry, vol. 39, no. 35, pp. 10812 10822, 2000.

[159] J. R. S. Day, P. P. Punjabi, A. M. Randi, D. O. Haskard, R. C. Lands, and K. M. Taylor, "Clinical inhibition of the seventransmembrane thrombin receptor (PAR1) by intravenous aprotinin during cardiothoracic surgery," Circulation, vol. 110, no. 17, pp. 2597-2600, 2004.

[160] J. W. Mitchell, N. Baik, F. J. Castellino, and L. A. Miles, "Plasminogen inhibits TNF $\alpha$-induced apoptosis in monocytes," Blood, vol. 107, no. 11, pp. 4383-4390, 2006.

[161] A. Boire, L. Covic, A. Agarwal, S. Jacques, S. Sherifi, and A. Kuliopulos, "PAR1 is a matrix metalloprotease-1 receptor that promotes invasion and tumorigenesis of breast cancer cells," Cell, vol. 120, no. 3, pp. 303-313, 2005.

[162] E. Yang, A. Boire, A. Agarwal et al., "Blockade of PAR1 signaling with cell-penetrating pepducins inhibits Akt survival pathways in breast cancer cells and suppresses tumor survival and metastasis," Cancer Research, vol. 69, no. 15, pp. 6223 6231, 2009.

[163] M. Tjwa, N. Sidenius, R. Moura et al., "Membraneanchored UPAR regulates the proliferation, marrow pool size, engraftment, and mobilization of mouse hematopoietic stem/progenitor cells," Journal of Clinical Investigation, vol. 119, no. 4, pp. 1008-1018, 2009.

[164] H. Yuan, K. M. Vance, C. E. Junge et al., "The serine protease plasmin cleaves the amino-terminal domain of the NR2A subunit to relieve zinc inhibition of the N-methyl-Daspartate receptors," Journal of Biological Chemistry, vol. 284, no. 19, pp. 12862-12873, 2009.

[165] L. Groc, L. Bard, and D. Choquet, "Surface trafficking of Nmethyl-d-aspartate receptors: physiological and pathological perspectives," Neuroscience, vol. 158, no. 1, pp. 4-18, 2009.

[166] M. Zhuo, "Plasticity of NMDA receptor NR2B subunit in memory and chronic pain," Molecular Brain, vol. 2, no. 1, article 4, 2009.

[167] A. Wortmann, Y. He, E. I. Deryugina, J. P. Quigley, and J. D. Hooper, "The cell surface glycoprotein CDCP1 in cancer Insights, opportunities, and challenges," IUBMB Life, vol. 61, no. 7, pp. 723-730, 2009.

[168] H. Liu, S. E. Ong, K. Badu-Nkansah, J. Schindler, F. M. White, and R. O. Hynes, "CUB-domain - Containing protein 1 (CDCP1) activates Src to promote melanoma metastasis," Proceedings of the National Academy of Sciences of the United States of America, vol. 108, no. 4, pp. 1379-1384, 2011.

[169] Y. Miyazawa, T. Uekita, N. Hiraoka et al., "CUB domaincontaining protein 1 , a prognostic factor for human pancreatic cancers, promotes cell migration and extracellular matrix degradation," Cancer Research, vol. 70, no. 12, pp. 5136-5146, 2010.

[170] Y. Awakura, E. Nakamura, T. Takahashi et al., "Microarraybased identification of CUB-domain containing protein 1 as a potential prognostic marker in conventional renal cell carcinoma," Journal of Cancer Research and Clinical Oncology, vol. 134, no. 12, pp. 1363-1369, 2008.
[171] O. V. Razorenova, E. C. Finger, R. Colavitti et al., "VHL loss in renal cell carcinoma leads to up-regulation of CUB domaincontaining protein 1 to stimulate $\mathrm{PKC} \delta$-driven migration," Proceedings of the National Academy of Sciences of the United States of America, vol. 108, no. 5, pp. 1931-1936, 2011.

[172] T. Uekita, L. Jia, M. Narisawa-Saito, J. Yokota, T. Kiyono, and R. Sakai, "CUB domain-containing protein 1 is a novel regulator of anoikis resistance in lung adenocarcinoma," Molecular and Cellular Biology, vol. 27, no. 21, pp. 7649-7660, 2007.

[173] T. Uekita, M. Tanaka, M. Takigahira et al., "CUB-domaincontaining protein 1 regulates peritoneal dissemination of gastric scirrhous carcinoma," American Journal of Pathology, vol. 172, no. 6, pp. 1729-1739, 2008.

[174] E. I. Deryugina, E. M. Conn, A. Wortmann et al., "Functional role of cell surface CUB domain-containing protein 1 in tumor cell dissemination," Molecular Cancer Research, vol. 7, no. 8, pp. 1197-1211, 2009.

[175] J. D. Hooper, A. Zijlstra, R. T. Aimes et al., "Subtractive immunization using highly metastatic human tumor cells identifies SIMA135/CDCP1, a $135 \mathrm{kDa}$ cell surface phosphorylated glycoprotein antigen," Oncogene, vol. 22, no. 12, pp. 1783-1794, 2003.

[176] C. H. Benes, N. Wu, A. E. H. Elia, T. Dharia, L. C. Cantley, and S. P. Soltoff, "The C2 domain of PKC $\delta$ is a phosphotyrosine binding domain," Cell, vol. 121, no. 2, pp. 271-280, 2005.

[177] Y. He, A. Wortmann, L. J. Burke et al., "Proteolysis-induced $\mathrm{N}$-terminal ectodomain shedding of the integral membrane glycoprotein CUB domain-containing protein 1 (CDCP1) is accompanied by tyrosine phosphorylation of its C-terminal domain and recruitment of Src and PKC $\delta$," Journal of Biological Chemistry, vol. 285, no. 34, pp. 26162-26173, 2010.

[178] A. Schmidt, F. Echtermeyer, A. Alozie, K. Brands, and E. Buddecke, "Plasmin- and thrombin-accelerated shedding of syndecan-4 ectodomain generates cleavage sites at Lys ${ }^{114}$ Arg115 and Lys129-Val ${ }^{130}$ bonds," Journal of Biological Chemistry, vol. 280, no. 41, pp. 34441-34446, 2005.

[179] A. N. Alexopoulou, H. A. B. Multhaupt, and J. R. Couchman, "Syndecans in wound healing, inflammation and vascular biology," International Journal of Biochemistry and Cell Biology, vol. 39, no. 3, pp. 505-528, 2007.

[180] C. Attali, C. Durmort, T. Vernet, and A. M. Di Guilmi, "The interaction of Streptococcus pneumoniae with plasmin mediates transmigration across endothelial and epithelial monolayers by intercellular junction cleavage," Infection and Immunity, vol. 76, no. 11, pp. 5350-5356, 2008.

[181] J. H. Im, W. Fu, H. Wang et al., "Coagulation facilitates tumor cell spreading in the pulmonary vasculature during early metastatic colony formation," Cancer Research, vol. 64, no. 23, pp. 8613-8619, 2004.

[182] J. M. Kirstein, K. C. Graham, L. T. MacKenzie et al., "Effect of anti-fibrinolytic therapy on experimental melanoma metastasis," Clinical and Experimental Metastasis, vol. 26, no. 2, pp. 121-131, 2009.

[183] G. A. Turner and L. Weiss, "Analysis of aprotinin-induced enhancement of metastasis of Lewis lung tumors in mice," Cancer Research, vol. 41, no. 7, pp. 2576-2580, 1981.

[184] T. H. Bugge, K. W. Kombrinck, M. J. Flick, C. C. Daugherty, M. J. S. Danton, and J. L. Degen, "Loss of fibrinogen rescues mice from the pleiotropic effects of plasminogen deficiency," Cell, vol. 87, no. 4, pp. 709-719, 1996.

[185] G. E. Blouse, K. A. Bøotkjaer, E. Deryugina et al., "A novel mode of intervention with serine protease activity: targeting 
zymogen activation," Journal of Biological Chemistry, vol. 284, no. 7, pp. 4647-4657, 2009.

[186] E. M. Conn, K. A. Botkjaer, T. A. Kupriyanova, P. A. Andreasen, E. I. Deryugina, and J. P. Quigley, "Comparative analysis of metastasis variants derived from human prostate carcinoma cells: roles in intravasation of VEGF-mediated angiogenesis and uPA-mediated invasion," American Journal of Pathology, vol. 175, no. 4, pp. 1638-1652, 2009.

[187] K. A. Botkjaer, S. Fogh, E. C. Bekes et al., "Targeting the autolysis loop of urokinase-type plasminogen activator with conformation-specific monoclonal antibodies," Biochemical Journal, vol. 438, no. 1, pp. 39-51, 2011. 

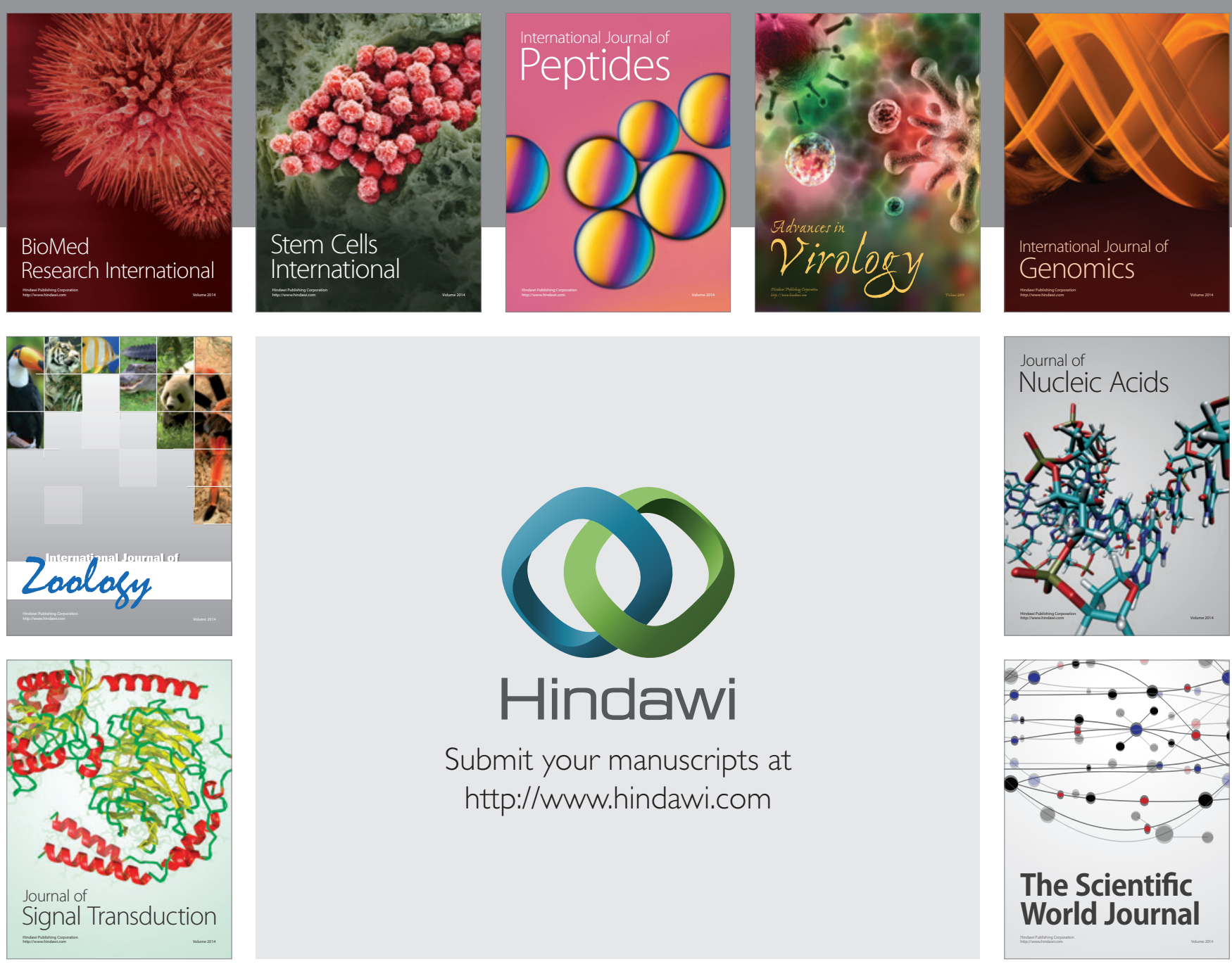

Submit your manuscripts at

http://www.hindawi.com
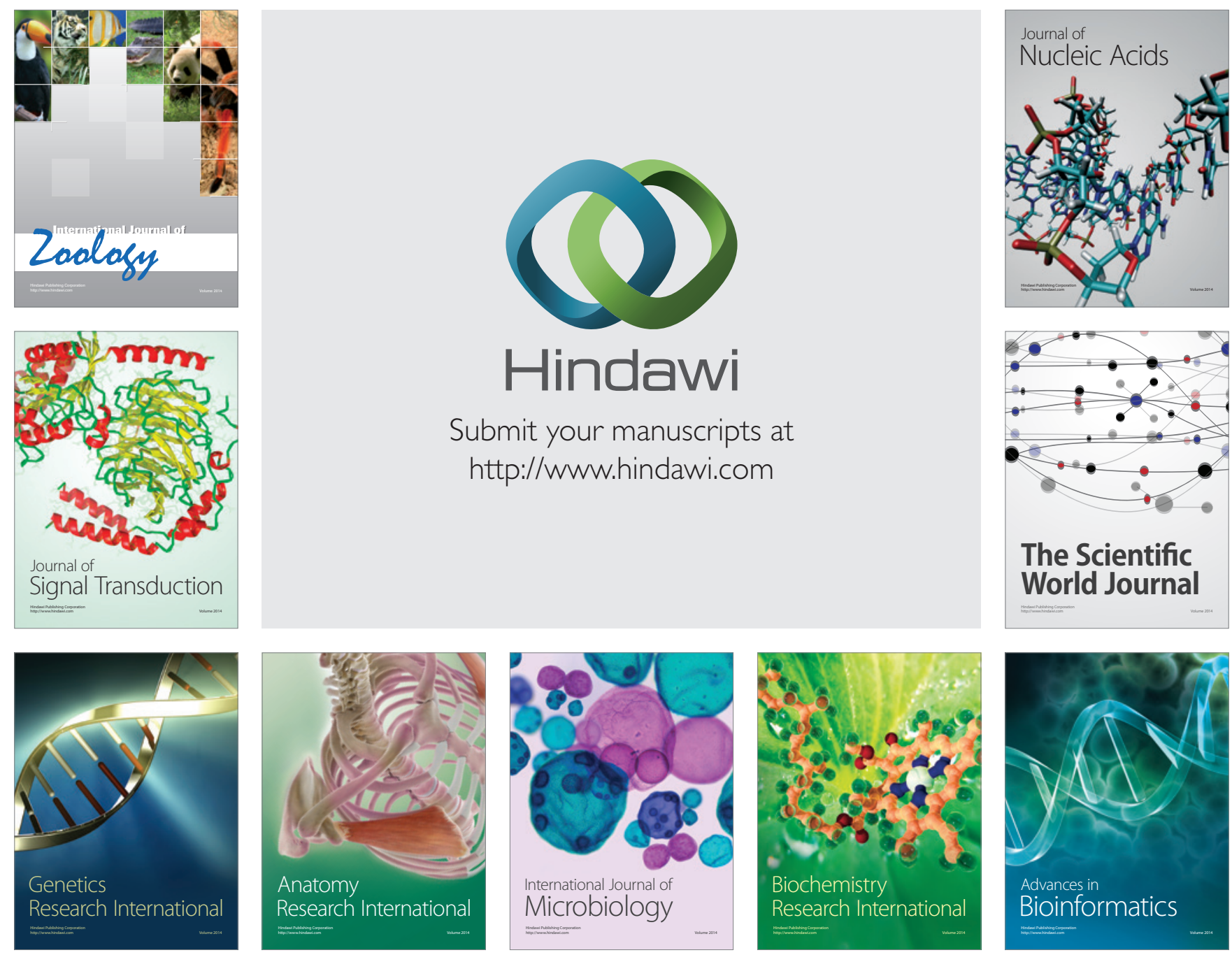

The Scientific World Journal
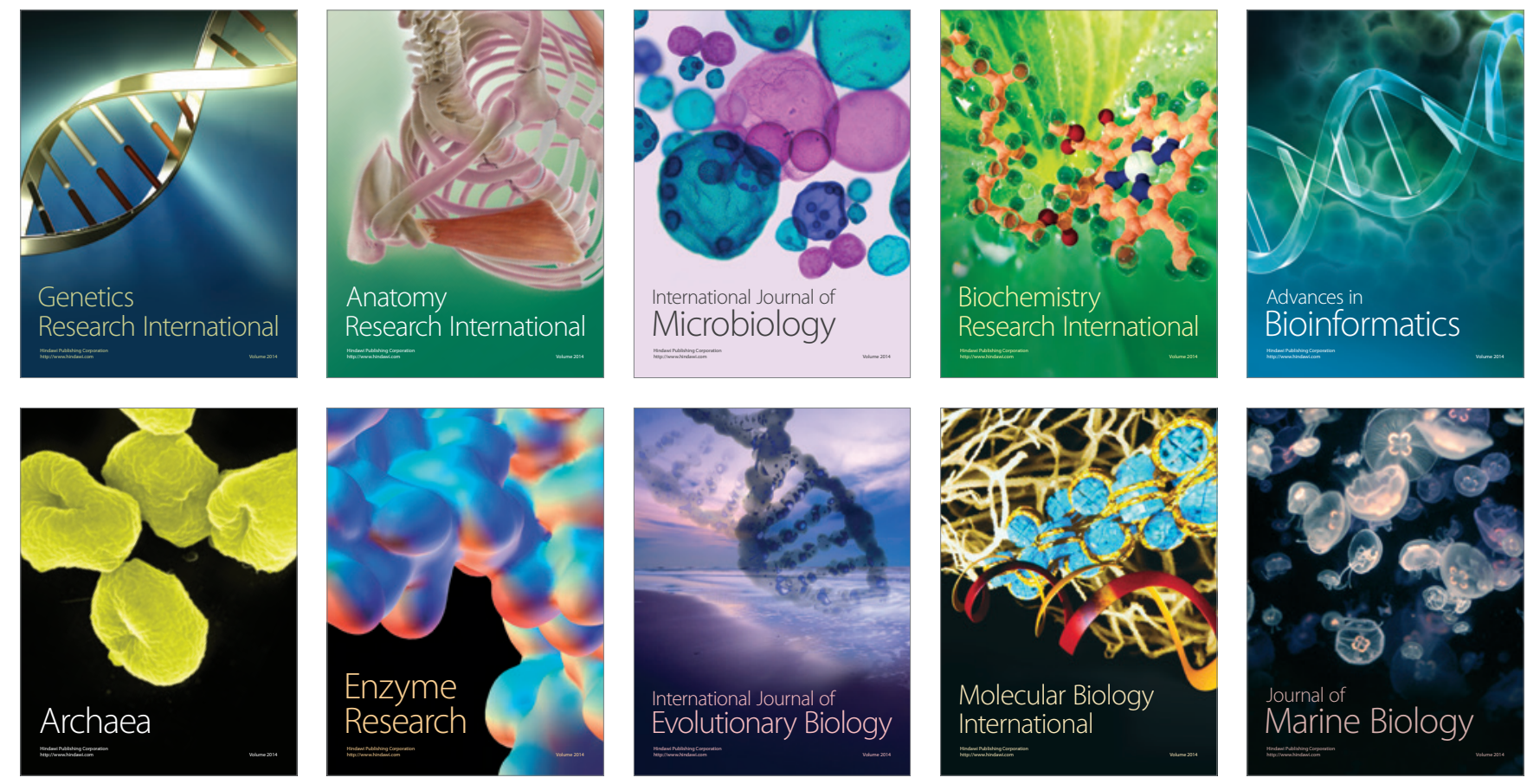